\title{
Are the Life and Death of an Early-stage Venture indeed in the Power of the Tongue?
}

\section{Lessons from Online Crowdfunding Pitches}

\author{
Gafni, Hadar; Marom, Dan; Sade, Orly
}

\author{
Document Version \\ Accepted author manuscript \\ Published in: \\ Strategic Entrepreneurship Journal
}

DOI:

10.1002/sej. 1293

Publication date:

2019

License

Unspecified

Citation for published version (APA):

Gafni, H., Marom, D., \& Sade, O. (2019). Are the Life and Death of an Early-stage Venture indeed in the Power of the Tongue? Lessons from Online Crowdfunding Pitches. Strategic Entrepreneurship Journal, 13(1), 3-23. https://doi.org/10.1002/sej.1293

Link to publication in CBS Research Portal

\section{General rights}

Copyright and moral rights for the publications made accessible in the public portal are retained by the authors and/or other copyright owners and it is a condition of accessing publications that users recognise and abide by the legal requirements associated with these rights.

\section{Take down policy}

If you believe that this document breaches copyright please contact us (research.lib@cbs.dk) providing details, and we will remove access to the work immediately and investigate your claim. 


\section{Are the Life and Death of an Early-stage Venture indeed in the Power of the Tongue?: Lessons from Online Crowdfunding Pitches}

\section{Hadar Gafni, Dan Marom, and Orly Sade}

Journal article (Accepted version)

This is the peer reviewed version of the following article: Are the Life and Death of an Early-stage Venture indeed in the Power of the Tongue? : Lessons from Online

Crowdfunding Pitches. / Gafni, Hadar; Marom, Dan; Sade, Orly. In: Strategic Entrepreneurship Journal, 14.05.2018, which has been published in final form at https://doi.org/10.1002/sej.1293

This article may be used for non-commercial purposes in accordance with Wiley Terms and Conditions for Self-Archiving.

Uploaded to Research@CBS: July २०18 


\title{
ARE THE LIFE AND DEATH OF AN EARLY STAGE \\ VENTURE INDEED IN THE POWER OF THE TONGUE?
}

LESSONS FROM ONLINE CROWDFUNDING PITCHES

\begin{abstract}
While presenting an initiative to potential backers, the entrepreneur can choose the extent to which she presents herself, versus presenting the idea. We investigate this decision and its effect on the success of fundraising on a leading crowdfunding platform (Kickstarter). We employ a textual quantification method validated by robustness tests. Our dataset was collected using custom software and includes over 20,000 online business pitches and their results. We find that in Kickstarter fundraising, entrepreneurs' descriptions matter - projects (especially art related) that frequently mentioned the entrepreneurs' name experienced higher rates of success, controlling for relevant variables.
\end{abstract}




\section{ARE THE LIFE AND DEATH OF AN EARLY STAGE \\ VENTURE INDEED IN THE POWER OF THE TONGUE?}

LESSONS FROM ONLINE CROWDFUNDING PITCHES

\section{MANAGERIAL SUMMARY}

Many entrepreneurs are interested to learn how to deliver a successful fund-raising pitch on crowdfunding platforms. We investigate the decision to mention frequently the entrepreneur's name and its effect on the success of fundraising on a leading crowdfunding platform (Kickstarter). We collected information about 20,000 online business pitches and their results. We find that in Kickstarter fundraising, entrepreneurs' descriptions matter projects (especially art related) that frequently mentioned the entrepreneurs' name experienced higher rates of success. We conducted an experiment that indicated that projects whose entrepreneur mentioned herself more substantially, were associated with higher level of trust and higher level of perceived knowledge of the entrepreneur. 


\section{INTRODUCTION}

Are contributors to a project in a reward-based crowdfunding platform being influenced by the entrepreneurs' description? Should entrepreneurs focus their business pitches on themselves?

When pitching the initiative to potential backers ${ }^{4}$, the entrepreneur attempts to optimize her ability to raise the needed amount, and thus may employ various methods to convince the backers to support the project. The entrepreneur may decide to emphasize the business idea in the pitch, or alternatively, the entrepreneur may center the presentation on her personage, calling upon her name, or past accomplishments. Given the limited time span ("elevator pitch"), this is a clear tradeoff. $^{5}$

Crowdfunding is a fundraising effort from an undefined large number of participants; each contributes a relatively small amount, through the internet and social networks. Recently, the use of crowdfunding to finance different aims is increasing dramatically. According to the Massolution Industry Report (2015), finance via crowdfunding was valued at more than $\$ 34$ billion USD in 2015. Our research focuses on Kickstarter, a leading crowdfunding platform. We used custom software to collect the investigated data. Our database consists of 16,111 successful projects, 4,113 failed projects, 18,496 entrepreneurs, 984,344 backers, and contributions that sum up

\footnotetext{
${ }^{4}$ The term "Backers" refers to financial contributors to reward-based crowdfunding projects.

${ }^{5}$ According to Kahneman (1973), attention is a scarce cognitive resource.
} 
to over $\$ 120$ million USD. The period investigated in this project is from the inception of Kickstarter in April 2009, until March 2012.

Researching the fundraising process through Kickstarter offers us a number of advantages: (1) We have the full pitch that was presented to the potential backers, which non-crowdfunding entrepreneurs typically keep classified. (2) We can focus on early stage financing, usually the stage least exposed to outsiders. (3) It enables us to have a very clear definition of success - the entrepreneur sets a goal and must reach it, otherwise the entrepreneur receives no funding. (4) We have a substantial number of ventures over a relatively short period of time.

To quantify the focus on the entrepreneur in the pitch, we use a technique that enables us to deal with large numbers of business pitches. Specifically, we count any mention of the entrepreneur's name. We examine this on three levels: first, a mention of the entrepreneur's name in the 'About' section of the project (a section that essentially serves as the business plan presented to potential backers); second, a mention of the entrepreneur's name in the first one hundred words of this section; third, a mention of the entrepreneur's name in the title of the project. We use these measures to answer several questions concerning the entrepreneurs' strategies and the campaign's success. Do entrepreneurs in different categories of projects present themselves differently in the pitch? Is the likelihood of financing success greater when additional information is provided on the relevant human capital? Does the success of a financing campaign depend on the type of project, on the amount of money sought, or on the entrepreneur's previous success? Obviously, in equilibrium, one would 
expect to find that entrepreneurs understand the factors that are important to the backers and adapt the pitch accordingly.

The word counting technique allows us to analyze thousands of entrepreneurial pitches. Nonetheless, three major arguments may be voiced against our counting mechanism: (1) The entrepreneur may highlight herself by using pronouns such as "I", "we", first or last names only, or any form that is not identical to the entry given as the entrepreneur's name on the site - we only identified exact matches. (2) The entrepreneur could highlight herself during the business pitch but only use her name a limited amount of times. For example, writing a few paragraphs about oneself while only mentioning their own name once. (3) Self-mentioning does not necessarily imply that the project idea is not also thoroughly described. (4) Self-mentioning could be affected by external reputation, and fundraising success could also be affected by the same entrepreneurial reputation factor. This argument entails the potential for influence in two opposite directions - a 'famous' entrepreneur (for example, a wellknown artist) could mention her name several times to leverage her external reputation. Conversely, there is no need to elaborate on a well-known figure, which may cause a very low number of self-mentions by a 'famous' entrepreneur. We employed several robustness tests to validate our mechanism with respect to these possible biases. First, we employed a human rating method on a sub-sample. Our raters were asked to examine business pitches and numerically evaluate the presentation of the entrepreneur and the business idea in the pitch. Our human coding results are positively correlated with our name counting technique. To cope with a 
potential bias from successful entrepreneurs described above, we examine the bottom goal decile (the lowest $10 \%$ of our sample in terms of goals), a sub-sample that certainly eliminates well-known entrepreneurs - and our conclusions remain unchanged. Using a sub-sample, we also examined the social network of 500 entrepreneurs to address the concern that mentions are related to external reputation. We did not find a significant correlation between the Twitter followers or Facebook fans of the entrepreneur and her self-mentions. One may argue that the investors' decisions to contribute to a small project may be entirely emotional. Hence, we repeat our analysis using only the top $10 \%$ of our sample in terms of goals set and document that our results hold.

We find that in our sample, the mean number of times that the entrepreneur's name is mentioned in the 'About' section in art-related projects is 0.728 , and is significantly higher than for technology-related projects (averaging 0.506). We find that experience with starting Kickstarter campaigns results in higher mentions. Furthermore, entrepreneurs whose last fundraising attempt on Kickstarter was successful mention their names significantly more in the 'About' section $(0.826>0.71)$ and in the first 100 words $(0.34>0.28)$. Moreover, the higher the funding goal, the more the entrepreneur's name is mentioned.

We use three different measures of success. The first, and likely most important measure in this context is the success in reaching the fundraising goal. This measure is estimated as a binary variable that equals 1 if the project managed to raise sufficient funds to match the original goal (and proceeded to receive the funds). For this type 
of project, the ability to fund the project will likely determine the "life or death" of the project. The second measure of success is the percentage pledged, which is calculated by dividing the sum pledged by the total goal. On Kickstarter, highly successful projects managed to raise substantially more than their original goals. The third is the number of backers who funded the project. Regardless of the measure of success we employ, the mentions of the entrepreneur's name matter, controlling for various control variables, which concern the project, its presentation, and the entrepreneur. We also document that in the multivariate analysis, we find that reaching the goal is significantly negatively correlated to the project being technology-related, even after controlling for the goal. It is also significantly negatively related to the size of the goal. When we separate the sample to technology and art related projects, the number of mentions only has a significant effect on the success of artistic projects.

We conducted an additional test to analyze the effect of the focus on the entrepreneur (which its proxy is mentions), and to deal with potential criticism of potential selection bias. We questioned subjects that were not previously familiar with the entrepreneur and the specific project to read and evaluate different selected pitches from our sample. The subjects' lack of previous knowledge is important to assure that all the information needed for their perception about the entrepreneur and the specific project was obtained solely from the text of the pitch. For the projects whose entrepreneur mentioned herself more substantially, the subjects indicated higher level of trust and higher level of perceived knowledge of the entrepreneur. This suggests 
that a high number of self-mentions increased the trust and the perception of familiarity of the respondents in the entrepreneur.

Our study contributes to the entrepreneurship and entrepreneurial finance literature in several aspects. First, our paper contributes to the academic literature on the influence of two of a firm's major assets - human and non-human capital, and investigates their relative importance to the success of a firm. ${ }^{6}$ Previous empirical academic literature focused on equity financing: Kaplan, Sensoy, and Stromberg (2009) investigated VC's and coined the term the "horse versus jokey dilemma". Marom (2012) confirmed their results using a different sample.

Clearly, the question is important beyond the VC world. Probably the most closely related paper from this literature to ours is Bernstein, Korteweg, and Laws (2017). They used a randomized field experiment to study 21 different capital-seeking startups via AngelList, an online platform that matches start-ups to angel investors. They found that investors respond strongly to information about the founding team, whereas they do not respond to information about either firm traction or existing lead investors. While both studies find that mentioning the entrepreneurs' names is indeed important, the papers complement one another; we use different methods of investigation, and focus on different leading crowdfunding platforms - equity-based crowdfunding (Bernstein et al.), versus rewards-based (this project). We find that entrepreneurs present themselves differently across categories, and by their prior entrepreneurial experience. Backers act on the information presented by the

\footnotetext{
${ }^{6}$ e.g., Rajan and Zingales $(2001,2012)$ and Penrose (1959).
} 
entrepreneur, and this affects the success of the funding campaign. Finally, our project provides evidence that supports the claims of many practitioners - that the entrepreneur's description is essential.

Second, our paper is closely related to the recent emerging literature that investigates the text provided by entrepreneurs in the crowdfunding pitch. While related literature focused on the style, or narrative (e.g Parhankangas and Renko (2017), Manning and Bejarano (2016), Allison et al (2015)), our approach is very different as we focus on the number of mentions of the entrepreneur name. Our paper also contributes to the literature on early stage financing in general, and crowdfunding in particular (e.g. Lambert and Schwienbacher (2010), Agrawal, Catalini and Goldfarb (2015), and Mollick (2014) among others). This growing literature uses crowdfunding activity to investigate early stage entrepreneurship.

CROWDFUNDING, KICKSTARTER MARKET STRUCTURE AND THE DATA DESCRIPTION

\section{Overview of crowdfunding}

Crowdfunding is an innovative funding mechanism that leverages the internet and social networks to raise funds from a large number of investors/backers/contributors, typically raising small amounts from each investor. Crowdfunding enables the entrepreneur to reach out to an undefined large number of investors/backers/ contributors, in addition to circles of family and friends. Initial fundraising through crowdfunding can help start-ups grow, perhaps even presenting an alternative to 
current seed funding solutions, such as Angel Investors, VCs, or governmental support. ${ }^{7}$ Shwienbacher and Larralde (2010) elaborate on the definition, evolution and key aspects of this funding mechanism.

Bradford (2012) categorizes crowdfunding into five types, distinguished by what investors are promised in return for their contributions: (1) The reward model: offering a certain perk to the backers in return for the contribution, but without interest or a share in the business' earnings. (2) The pre-purchase model: contributors receive the product that the entrepreneur is producing, prior to its marketing to the general public. (3) The lending model: a loan is given to the entrepreneur through funding by one or more lenders. (4) The equity model: this model offers investors a share of the venture. (5) The donation model: contributors receive nothing in return for their contribution. Dushnitsky et al. (2016) indicate that the level of activity for each of these dominant crowdfunding models varies significantly in different countries.

\section{Market structure - Kickstarter}

Kickstarter is one of the world's most prominent crowdfunding platforms ${ }^{8}$. It acts as an intermediary between entrepreneurs seeking funding and potential project backers, using a reward-based crowdfunding mechanism. Campaigns posted on Kickstarter aim to fund a specific project, rather than a firm's activity or educational or medical costs. Projects featured on Kickstarter belong to 13 predetermined (by the platform)

\footnotetext{
${ }^{7}$ For example, Touchfire, a company that created a typing device for the iPad, is now an established firm and attributes much of their initial success to the crowdfunding model.

${ }^{8}$ Website: http://www.kickstarter.com
} 
categories, each featuring its own section and sub-categories, which range from artistic projects (i.e., music, film, or art) to technological projects (primarily product design and gadgetry). Kickstarter utilizes an "all-or-nothing" funding mechanism. Entrepreneurs receive funding only if they reach their funding goal within the allotted investment time frame. If the investment goal is not reached, funds are then returned to the backers. When joining Kickstarter, entrepreneurs are required to provide a project overview, a funding goal, and timeframe for investment (1-60 days). Entrepreneurs are strongly encouraged to provide their personal history, a history of the project, and other supplemental media. The entrepreneur provides the potential backers with a menu that discusses what he or she will receive for different levels of investment. These menus generally begin at a minimum of several dollars and increase to a level that depends on the investment.

\section{Data description}

Our database consists of 16,111 successful projects, 4,113 failed projects, 18,496 entrepreneurs, 984,344 investors, and contributions that sum up to over 120 million dollars. The period investigated in this project is three years, from the inception of Kickstarter, in April 2009, until March 2012. We used custom-made software to download the relevant data during March of 2012. All textual data from the available projects on the site were downloaded, as well as data on the creators of the projects and backers. It is important to note that Kickstarter only offers direct access to projects that are currently raising funds or successful projects - and not to failed ones. 
We bypass this limitation by using the list of links to projects that the funders have invested in and collecting the same information from them, via our custom-made software. Some of these projects are failed projects, meaning that we managed to download a substantial number of failed projects through a multi-stage downloading process. Thus, our database consists of all successful projects and all failed projects that received at least one investment by an investor who funded a successful or an ongoing project in our database $e^{9,10 .}$

The average requested funding (funding goal) in our full sample was $\$ 8,047$ (the median is $\$ 3,000$, and the maximum is $\$ 21,474,836$ ), while the average funding requested for successful projects was $\$ 5,061$ (median is $\$ 3,000$ ). A successful project attracted an average of 99 backers (median 51), while the failed projects only received interest from an average of 20 backers (median 9). The sets of variables used to describe each project are available in Appendix A.

As reported in Table 1, the technological projects set significantly higher goals than the artistic ones $(12,786>6,650)$, and although they represent $5.2 \%$ of the projects on the site, they account for $17.6 \%$ of the funds pledged. Projects in the gaming category set their goals higher than the other categories, at an average of $\$ 43,910$. The artistic category is dominated by music and film/video projects and includes most projects

\footnotetext{
${ }^{9}$ We are only unable to locate the URL of a project in cases where the project failed and did not receive any requests for funding from any known investor in our database. This may result in an underrepresentation of failed projects (or very unsuccessful projects) in the data, primarily from the initial years of Kickstarter activity. We performed robustness tests on sub-samples of our data and found that our main results hold.

${ }^{10}$ According to official Kickstarter statistics, http://www.kickstarter.com/help/stats, the success rate is $44 \%$, while in our dataset, we can only observe a $20 \%$ failure rate. This bias could be explained by the over 10,000 projects that were not funded at all. These projects would likely be screened out of our dataset even if we could gather them.
} 
on Kickstarter. The mean goal set in any of the artistic categories is significantly lower than those in the gaming and technological categories, as is the mean sum pledged.

[Table 1]

\section{QUANTIFYING THE ENTREPRENEURIAL PITCH}

\section{Quantification method}

The landing page of a particular project on Kickstarter's website is the equivalent of a common start-up's business plan and investment presentation. This is where the entrepreneurs pitch their idea to raise funds. The Kickstarter platform provides the entrepreneurs with five potential spaces they can utilize and elaborate their project in: (1) Basics: project title, location and overall funding goal; (2) Video or photo; (3) 'About' section: textual presentation of the project and/or the entrepreneur; (4) Perks: the reward for each funding level; (5) Entrepreneur's section: basic details and selfdescription. While attempting to estimate the presentation of the entrepreneur in the pitch, we focus on the 'About' section, where we can observe the differences among different presentations. Written by the entrepreneur, the text in the 'About' section accounts for most of the space on the page. Although the space in this section is not limited, the readers' capacity is, and the entrepreneur must make the best use of this section to highlight important material.

[Figure 1] 
It is not trivial to quantify the space devoted to description of the entrepreneur relative to that of the project. The variable we used to quantify this choice is the entrepreneur's name. To illustrate different choices, we took screenshots of the first pages of two different projects, both in the Comics category. The first (Figure 1a) is a project by Daniel Johnston. Daniel's name is mentioned in the project's title, four times in the first two paragraphs of the 'About' section, and once in the description of the perks. A user visiting the project's page will be unable to miss the name of the creator. The alternative approach is demonstrated on Richard Ankney's project page (Figure 1b). When a user visits Richard's page, she will see the creator's name mentioned once, in the mandatory name of entrepreneur field. Ankney's name is not mentioned in the 'About' section; instead, he uses the space to describe the plot of his novel and future plans for the series.

Entrepreneurs are divided into three types when choosing the author name that appears on their project page: (1) the individual name of the entrepreneur, in the case that there is only one entrepreneur, or one is very dominant; (2) multiple names of entrepreneurs; (3) the name of an organization (a band, a company, a group, etc.). For the $1^{\text {st }}$ and $3^{\text {rd }}$ types, we identified the name in the text and counted how many times it appeared. For the $2^{\text {nd }}$ type, a group of several entrepreneurs, we isolated the first individual's name and counted it to maintain consistency and compare and contrast with the former types. Our conjecture is that the more the entrepreneur's name is mentioned, the more emphasis the pitch places on her. 
We use two other methods as additional measures. We tracked the number of selfmentions in the first 100 words of the 'About' section only, as it can be seen of the first page of a business plan, i.e. the most important part of the section. We also assessed whether the entrepreneur was mentioned in the title of the project.

[Table 2]

Table 2 reports the summary of the methods. In all three measures, the average number of mentions is higher for successful projects than failed ones. Moreover, there is a significant positive correlation amongst the three methods. The correlation between the first measure (the 'About' section) and the second (only the first 100 words of that section) is 0.673 . Between the first and the third (the title of the project), the correlation is 0.34 , and the correlation between the second and the third is 0.367 . We encountered a team of entrepreneurs stated in the 'About' page in fewer than 5\% of the projects. It seems that while many of the projects were founded by a team, most of the groups decided to only present the leader's name or the group's name. To assess whether counting the first entrepreneur mentioned is similar to counting any other entrepreneur from the group, we isolated the second name and employed the same quantification measures. We find that the second name behaves exactly as the total sample: in all three measures, the successful projects mentioned the entrepreneur more than failed ones did. Further, we focused on the sub-sample of projects with two entrepreneurs' names and conducted t-tests for any differences in the number of mentions. None of the differences in the three measures were significant. Therefore, 
we report the results of the measure when we only used mentions of the first entrepreneur's name.

\section{Human coding verification test}

As mentioned above, our text analysis method may face two different challenges. The first relates to the text mechanism procedure; our counting method ignores such cases as referring to the entrepreneur in the third person, with a nickname, or first name only. Further, our measure does not take sentence interpretation into account. It could be argued that a mention count could be biased if long paragraphs that details the entrepreneur's story were to include only one mention, and conversely, a brief paragraph on the entrepreneur that includes several mentions. Second, one may argue that finding numerous mentions of the entrepreneur's name does not necessarily mean that the project's idea is not also thoroughly described. To evaluate the potential effects of these challenges on our results, we conduct a human coding robustness test (similar in its spirit to the human coding methods in Ravina (2012) and subsequently in Duarte et al. (2012)). The main purpose of the test was to ask human raters to evaluate entrepreneur pitches that were part of our sample and to do so on a scale contrasting emphasis on the entrepreneurs vs. the business idea.

We conducted the test with the participation of 100 technology-oriented workers and managers from a large high-tech organization. All of the reviewers had a technology education, while some of them were also students or MBA graduates. $62 \%$ of the reviewers were men. We did not find any variance in the results due to differences in 
their backgrounds, genders or education. Overall, we rated 100 entrepreneurial pitches from the technology and art categories: 50 from the Technology category, and 50 from the Dance category. We classified the projects from our sample to quadrants of mention counts to ensure that we had sufficient variation in the number of mentions in the pitches to be rated by the group. We then randomly selected 100 projects from the top and bottom quadrants of each category. Each entrepreneurial pitch was rated by 5 reviewers, yielding a total of 500 ratings. Each rater received a brief textual and oral introduction to Kickstarter and was asked to rate 5 entrepreneurial pitches using the following three questions, with the responses to which were on a scale from 1 to 7: (Q1) Please rate on a scale of 1 to 7 which of the following was emphasized more in the project page - the project or the creator of the project. (Q2) Please rate the degree of emphasis on the creator on the project page. (Q3) Please rate the degree of emphasis on the project on the project page. The first question (Q1) scales the relative emphasis between the project and the entrepreneur, and the two other questions examine the weight of each component - entrepreneur (Q2) and project (Q3).

The human raters' results support our name-counting technique. The responses to Q2 indicate that the mention counting is significantly correlated (0.54) with the human perceptions of the pitches (see Figure 2). ${ }^{11}$ The results demonstrate the similarity of human perceptions to the self-mention counts.

[Figure 2]

\footnotetext{
${ }^{11}$ The mean of the score for Q2 for cases that the name is mentioned in the title is significantly higher than cases that the name is not mentioned in the title, which is consistent with our total mentions findings.
} 
Moreover, as expected, the negative (-0.29) correlation between the responses to Q3 and the number of mentions indicated that the less the entrepreneur is mentioned, the more the description of the actual project idea was highlighted and discussed in depth. We also verified that these results were independent of the category of the project; when the number of mentions of the entrepreneur is high, the entrepreneur is perceived as more highlighted than the project's idea in both the Dance and Technology projects.

Our test results indicate that both potential arguments against our text mining technique were unsubstantiated. The highly positive correlation found between the number of mentions and emphasis on the entrepreneur (Q2) indicates that although we certainly missed some self-references (as we do not count pronouns), the name counting technique is consistent with human perceptions. As we observed a negative correlation between the number of entrepreneur mentions and the level of emphasis on the project idea $(\mathrm{Q} 3)$ - the more the entrepreneur was mentioned, the less the raters were exposed to the project idea. We can attribute this to the limited attention of every person who is given a pitch of any type - focusing on one thing takes attention from another. Cronbach's alpha measures the correlation between all raters and is widely used in the literature to measure whether ratings from different individuals yield similar results. Our result, 0.9146, validates the internal consistency, or reliability, of our sample of raters. 


\section{ENTREPRENEURIAL PITCH AND MENTIONS}

\section{Past experience and prior success}

The serial entrepreneurship literature indicates that experience matters. ${ }^{12} \mathrm{We}$ compare the effect of previous success to previous failures, or novice entrepreneurs. We only consider experience with Kickstarter projects. Entrepreneurs that had previous projects on Kickstarter tend, on average, to mention their names more and there is a clear positive trend of mentions and experience. The average number of self-mentions increases with each previous project, whether it was a success or a failure (from an average of 0.527 in the about section ( 0.21 first 100 words) for 0 previous success to 0.825 ( 0.23 first 100 words) for previous 3 successes or 0.785 ( 0.24 first 100 words) for an experience of 3 projects regardless of success). The results are consistent with the theory mentioned above regarding the legitimacy and perceived advantages of serial entrepreneurs, who emphasize their background as a vital signal to potential investors. Learning could be another explanation for this phenomenon, while even failed entrepreneurs are more likely to mention themselves more.

\footnotetext{
${ }^{12}$ Packalen (2007) argues that a company's legitimacy is largely based on the previous achievements of its founders, especially in the early stage. Hsu (2007) demonstrates that serial entrepreneurs not only are more likely to obtain venture finance but also obtain better valuations. Zhang (2011) argues that entrepreneurs with prior firm-founding experience are expected to have additional skills and social connections that may provide an advantage in efforts to raise venture capital. Gompers, Kovner, Lerner and Scharfstein (2010) find that the previously successful entrepreneurs are more likely to succeed, thanks to their market timing skills. Paik (2014) examines VC-backed companies in the US semiconductor industry and finds that serial entrepreneurs perform better. Eesley and Roberts (2012) investigated talent versus experience.
} 


\section{Project category}

Some have questioned whether the importance of the human capital, relative to nonhuman capital, is similar across different categories (e.g. Wasserman et al. (2001) and Kaplan, Stromberg and Sensoy (2009)). The mean number of times a name is mentioned in the artistic categories in our sample is 0.729 , which is significantly higher than that in the technological category (averaging 0.506), suggesting the entrepreneurs in the Artistic category prefer to mention themselves more than the entrepreneurs in the Technological category. This may be a testament to the nature of their projects, suggesting that while the creator of the technological project can present a prototype of the product, a screenwriter is more likely to focus on her past works or resume. Another potential explanation is related to the easiness of human capital replacement. It may be easier to replace the entrepreneur in a technological project if the idea is appealing, rather than the artist. As a robustness test, we compared the human rating results of the Dance projects to those of the Technology projects, using t-tests to analyze the significant differences. The responses of our human raters indicated that the entrepreneurs of the dance projects were perceived to be highlighted more in the investment pitch than the entrepreneurs of technological projects were, and consistently, the technological projects' ideas were featured much more than the Dance projects' concepts. 


\section{Funding goal}

Entrepreneurs set a funding goal at the beginning of each crowdfunding campaign. The goal is crucial due to Kickstarter's "all or nothing" method. Our conjecture is that a higher funding goal requires some elaboration concerning the entrepreneurial team. It is reasonable to believe that a project that aims to raise a large amount of seed funding will have to present a strong team with proven execution experience or capabilities. As expected, there is a steady rise in the number of mentions as the entrepreneur attempts to raise more capital, from 0.499 in the first goal decile to 0.837 in the 10th, with a monotonic rise between them. Mentions in the title and the first 100 words seem to identify fewer mentions among projects with higher goals, which may be a result of the high proportion of technological projects in the higher goal category. As the category is correlated with the goal, we also verify the aforementioned relationship by investigating the relative goals in each category. Most of these results are consistent with previous findings - the higher the goal, the more the entrepreneur's name is mentioned. Furthermore, all means in the $>150 \%$ portion (relative to the categories' goal mean) are significantly higher than those in the $<50 \%$.

\section{Video}

Entrepreneurs on Kickstarter are advised to add a visual illustration of their initiative, in the form of an image or a video. Most (approximately $82 \%$ of our sample) choose to do so. The impacts that "entrepreneurial passion" and general preparedness have on the investor are central to understanding the extent to which the investor may be 
affected by the general traits or personality of the entrepreneur (e.g., Chen, Yao, and Kotha (2009), and Cardon, Sudek, and Mitteness (2009)). In our sample, projects that feature a video also tend to mention the entrepreneur's name more frequently. As such, the mean mentions are higher in all three measures. The most significant is in the number of mentions on the about page; projects with a video have an average of 0.755 mentions, while the average of those without video self-mentions is 0.528 .

\section{Multivariate analysis}

To evaluate what affected the number of mentions, we estimate the following models for each project $i$ and entrepreneur $j$ :

1. NumberOfMentions $_{i j}=f\left(\alpha_{1}\right.$ dummy $\left(\right.$ Technology $\left._{i}\right)+\alpha_{2}$ Goal $_{i}+$ $\alpha_{3}$ PreviousSuccess $_{j}+\alpha_{4}$ dummy $_{\left(\text {Video }_{i}\right)}+\alpha_{5}$ TotalWords $_{i}+$ $\alpha_{6}$ dummy $\left(\right.$ Website $\left._{i}\right)+\alpha_{7}$ dummy $\left.\left(U S A_{i}\right)+\varepsilon_{i j}\right)$

2. NumberOfMentionsInFirst100Words $s_{i j}=f\left(\alpha_{1}\right.$ dummy(Technology $\left.y_{i}\right)+\alpha_{2}$ Goal $_{i}+$ $\alpha_{3}$ PreviousSuccess $_{j}+\alpha_{4}$ dummy $\left(\right.$ Video $\left._{i}\right)+\alpha_{5}$ dummy $\left(\right.$ Website $\left._{i}\right)+$ $\left.\alpha_{6} d u m m y\left(U S A_{i}\right)+\varepsilon_{i j}\right)$

3. NumberOfMentionsInTitle N $_{j}=f\left(\alpha_{1}\right.$ dummy $\left(\right.$ Technology $\left._{i}\right)+\alpha_{2}$ Goal $_{i}+$ $\alpha_{3}$ PreviousSuccess $_{j}+\alpha_{4}$ dummy $\left._{\left(\text {Video }_{i}\right.}\right)+\alpha_{5}$ dummy $\left(\right.$ Website $\left._{i}\right)+$ $\alpha_{6}$ dummy $\left.\left(U S A_{i}\right)+\varepsilon_{i j}\right)$

Where:

$\underline{\text { NumberOfMentions }}=$ the number of mentions in the 'About' section. $\underline{\text { NumberOfMentionsIn100Words }}=$ identical to as NumberOfMentions, except that it only scans the first 100 words in the 'About' section. NumberOfMentionsInTitle $=$ equals 1 if the entrepreneur is mentioned in the title of the project, 0 otherwise. $\underline{\text { Technology }}=$ equals 1 if the category of the project belongs to the Technological 


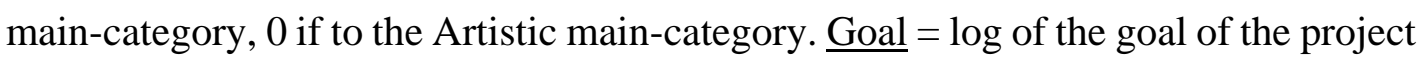
in $\$$. PreviousSuccess $=$ the number of previous successes the entrepreneur had on the Kickstarter platform. $\underline{\text { Video }}=$ equals 1 if the entrepreneur posted a video on the project's page, 0 if not. $\underline{\text { TotalWords }}=\log$ of the total number of words in the 'About' section. $\underline{\text { Website }}=$ equals 1 if the user provides a website link, 0 otherwise. $\underline{\text { USA }}=$ equals 1 if the project is based in the USA, 0 otherwise.

The equations were estimated using OLS, Poisson regression (as we count the number of mentions), and Tobit regression (as our sample is truncated at zero), see Table 3. The negative and significant coefficients of the Technological variables indicate that the projects in the technological categories are less likely to mention the entrepreneur in the title and the 'About' section of their project's page. This coefficient is stable across all regressions. Our results suggest that entrepreneurs in different categories present their projects differently.

[Table 3]

In addition, the previous success coefficients are positive and significant, confirming the hypothesis regarding the self-mentioning of serial entrepreneurs. Other variables remain consistent with their univariate results. The number of mentions is positively correlated with the goal, video presence and number of previous successes.

\section{MEASURING AND ESTIMATING SUCCESS}

Next, we examine the determinants for success, especially regarding the entrepreneurs' mentions. The following three variables were employed to assess 
whether a project was successful: (1) Success in reaching the funding goal: a binary variable that equals 1 if the project managed to raise sufficient funds to match the original goal and, as a result, received the funds. (2) Logarithm of \% Pledged: dividing the sum pledged by the goal, and taking the logarithm. (3) Logarithm of Backers: the logarithm number of backers who funded the project.

We find that the likelihood that an artistic project will reach its goal $(0.81)$ is significantly higher than that of their technological rivals (0.637). The gaming category is situated between the artistic category and the technological one $(0.658)^{13}$. Table 4 presents the different categories by our measures of success.

[Table 4]

These findings are partially explained by the mean goal. As the technological projects set significantly higher goals than the artistic projects $(12,785>6,650$, significant), the entrepreneurs of technological projects find it more difficult to raise sufficient funds to meet their goals. The gap in the means of the goals may be clarified by the next column - the mean of the share of the sum pledged out of the goal. Interestingly, although the chances of success for the technological categories are lower, the mean of the percentage pledged is higher. This is due to a minority of projects that enjoyed very high pledging (over 1000\%). This trend can also be observed in the "number of backers" variable, which is significantly higher for the technological categories.

\footnotetext{
${ }^{13}$ It should be noted that because of extraction limitations, the reported rate of success is probably higher in our paper than in reality, as we only include failed projects which received funding (but did not reach their goal). However, this data selection should not be correlated with specific category.
} 
We examined the correlation between the fundraising goal and the projects' success. The higher the goal, the lower the likelihood that the project will reach that goal from an $89 \%$ likelihood for the lowest $10 \%$ of goals, to a $54 \%$ likelihood for the highest $10 \%$ of goals. The mean of the percentage pledged also declines (from 15.2 to 0.8 ), while the mean number of backers increases monotonically from 21.2 to 276.7 backers for projects in the top decile. We verified this finding by analyzing the goal differences within the categories, relative to each category's goal mean. The likelihood of success declined from $84 \%$ with 45 backers when the project's goal was less than $50 \%$ of its category mean goal, to $66 \%$ with 190 backers at a goal over $150 \%$ of the category mean.

Entrepreneurs that include videos on their pages (82\%) tend to be more successful in their fundraising; their likelihood of success (81.4\%) and number of backers (91.6) are significantly higher than projects that do not feature a video on their project pages. The number of backers is positively and significantly affected when a patent is mentioned in the technology-related projects (521 when 'patent' is mentioned and 231 when not). ${ }^{14}$ However, the results indicate that there is no significant difference in the likelihood of success. This may be because the goals in such cases are much higher. Surprisingly, a serial entrepreneur using Kickstarter, who had a previous successful Kickstarter project, is not more likely to reach the funding goal on a new Kickstarter project (80\%) than novice entrepreneurs (81\%). One reason for this finding may relate to the level of the new goal, which is generally higher in post-success projects.

\footnotetext{
${ }^{14}$ See Conti, Thursby, and Rothaermel (2013) for a discussion about patents as signals.
} 
Nevertheless, if the previous project was a failure, the likelihood of success declines to $50 \%$. Successful serial entrepreneurs have a greater number of backers (113) on average compared to novice entrepreneurs (who have an average of 83 backers), and serial entrepreneurs whose previous projects failed (average of 42 backers). The probabilities increase from $51 \%$ for novice entrepreneurs, to $80 \%$ for those with a minimum of three successful projects featured on their resume.

\section{Multivariate analysis}

The following regressions were estimated to test the effects of the project presentation variables on our success measures. ${ }^{15}$

4. Probability of reaching the goal for project $i$ by entrepreneur $j$ :

$$
\begin{aligned}
& \operatorname{Pr}(\text { Success })_{i j} \\
& =f\left(\beta_{1} \text { Technological }_{i}+\beta_{2} \text { ThreeMentions }_{i j}+\beta_{3} \text { Goal }_{i}+\beta_{4} \text { PreviousSuccess }_{i j}+\beta_{5} \text { Video }_{i}\right. \\
& \left.+\beta_{6} \text { TotalWords }_{i}+\beta_{7} \text { Website }_{i}+\beta_{8} U S A_{i}+\varepsilon_{i j}\right) \\
& \operatorname{Pr}(\text { Success })_{i j} \\
& =f\left(\beta_{1} \text { Technological }_{i}+\beta_{2} \text { NumberOfMentions }_{i j}+\beta_{3} \text { Goal }_{i}+\beta_{4} \text { PreviousSuccess }_{i j}\right. \\
& \left.+\beta_{5} \text { Video }_{i}+\beta_{6} \text { TotalWords }_{i}+\beta_{7} \text { Website }_{i}+\beta_{8} U S A_{i}+\varepsilon_{i j}\right) \\
& \operatorname{Pr}(\text { Success })_{i j} \\
& =f\left(\beta_{1} \text { Technological }_{i}+\beta_{2} \text { dummy (Mentions }\right)_{i j}+\beta_{3} \text { Goal }_{i}+\beta_{4} \text { PreviousSuccess }_{i j} \\
& \left.+\beta_{5} \text { Video }_{i}+\beta_{6} \text { TotalWords }_{i}+\beta_{7} \text { Website }_{i}+\beta_{8} U S A_{i}+\varepsilon_{i j}\right)
\end{aligned}
$$

5. Percentage of sum pledged out of the entire goal:

$$
\begin{array}{r}
{\text { Perc }(\text { PledgeRatio })_{i j}} \\
=f\left(\beta_{1} \text { Technological }_{i}+\beta_{2} \text { ThreeMentions }_{i j}+\beta_{3} \text { PreviousSuccess }_{i j}+\beta_{4} \text { Video }_{i}\right. \\
\left.+\beta_{5} \text { TotalWords }_{i}+\beta_{6} \text { Website }_{i}+\beta_{7} \text { USA }_{i}+\varepsilon_{i j}\right)
\end{array}
$$

\footnotetext{
${ }^{15}$ For robustness, Equation 4 was estimated using OLS, Logit and Probit; Equation 5 was estimated using OLS and Tobit; Equation 6 was estimated using OLS and Poisson.
} 


$$
\begin{aligned}
& \text { Perc(PledgeRatio })_{i j} \\
& =f\left(\beta_{1} \text { Technological }_{i}+\beta_{2} \text { NumberOfMentions }_{i j}+\beta_{3} \text { PreviousSuccess }_{i j}+\beta_{4} \text { Video }_{i}\right. \\
& \left.+\beta_{5} \text { TotalWords }_{i}+\beta_{6} \text { Website }_{i}+\beta_{7} U S A_{i}+\varepsilon_{i j}\right) \\
& \text { Perc(PledgeRatio })_{i j} \\
& =f\left(\beta_{1} \text { Technological }_{i}+\beta_{2} \text { dummy }_{\text {(Mentions }}\right)_{i j}+\beta_{3} \text { PreviousSuccess }_{i j}+\beta_{4} \text { Video }_{i} \\
& \left.+\beta_{5} \text { TotalWords }_{i}+\beta_{6} \text { Website }_{i}+\beta_{7} U S A_{i}+\varepsilon_{i j}\right)
\end{aligned}
$$

\section{Number of backers:}

$$
\begin{aligned}
& \text { Number(backers) })_{i j} \\
& =f\left(\beta_{1} \text { Technological }_{i}+\beta_{2} \text { ThreeMentions }_{i j}+\beta_{3} \text { Goal }_{i}+\beta_{4} \text { PreviousSuccess }_{i j}+\beta_{5} \text { Video }_{i}\right. \\
& \left.+\beta_{6} \text { TotalWords }_{i}+\beta_{7} \text { Website }_{i}+\beta_{8} \text { USA }_{i}+\varepsilon_{i j}\right) \\
& \text { Number (backers) })_{i j} \\
& =f\left(\beta_{1} \text { Technological }_{i}+\beta_{2} \text { NumberOfMentions }_{i j}+\beta_{3} \text { Goal }_{i}+\beta_{4} \text { PreviousSuccess }_{i j}\right. \\
& \left.+\beta_{5} \text { Video }_{i}+\beta_{6} \text { TotalWords }_{i}+\beta_{7} \text { Website }_{i}+\beta_{8} U S A_{i}+\varepsilon_{i j}\right) \\
& \text { Number (backers) }{ }_{i j} \\
& =f\left(\beta_{1} \text { Technological }_{i}+\beta_{2} \text { dummy }_{\text {(Mentions }}{ }_{i j}+\beta_{3} \text { Goal }_{i}+\beta_{4} \text { PreviousSuccess }_{i j}\right. \\
& \left.+\beta_{5} \text { Video }_{i}+\beta_{6} \text { TotalWords }_{i}+\beta_{7} \text { Website }_{i}+\beta_{8} U S A_{i}+\varepsilon_{i j}\right)
\end{aligned}
$$

Where:

$\underline{\text { Success }}=$ dummy equal to 1 if the project reached its goal. PledgeRatio $=\log$ of the division of the sum pledged by the goal of the project. $\underline{\text { Backers }}=\log$ of the number of backers. ThreeMentions $=$ a binary variable that takes value 1 if the entrepreneur is mentioned at least 3 times in the 'About' section. ${ }^{16}$ Mentions $=$ number of mentions. dummy(Mentions) $=$ series of dummy variables that each takes the value 1 if the number of mentions is equal to the number presented. Technology $=$ equals 1 if the category of the project belongs to the Technological main-category, 0 if to the Artistic

\footnotetext{
${ }^{16} \mathrm{We}$ estimated additional variations of this variable and describe the results below; however, in the table we present the "at least 3 mentions" case. This choice is motivated by the human rater test; the average mentions in the cases that raters assigned the value 4 or above was 2.7 or above.
} 
main-category. $\underline{\mathrm{Goal}}=\log$ of the goal of the project in U.S. \$. PreviousSuccess $=$ the number of previous successes the entrepreneur had. $\underline{\text { Video }}=$ equals 1 if the entrepreneur posted a video on the project's page, 0 if not. TotalWords $=\log$ of the total number of words in the 'About' section. $\underline{\text { Website }}=$ equals 1 if the user provides a website link, 0 otherwise. $\underline{\text { USA }}=$ equals 1 if the project is based in the USA, 0 otherwise.

Results are provided in Table 5. We find a positive coefficient on the mention variable for the three different success measures and for the three different measures of mentions. Even when controlling for all other variables, the results remain significant, demonstrating the importance of the entrepreneur's self-description in the fundraising process ${ }^{17}$. Other variables are less consistent across categories. Technology-based projects are less likely to meet their goals, but are more likely to attract a higher number of backers. We noted an increased value of the funds to goal ratio in the technological categories, while in the full regression, the results suggested that the artistic projects raised, on average, more funds relative to their goals.

\section{[Table 5]}

The size of the goal has a negative relationship with the probability of obtaining set goal, and a positive one with the number of backers. The number of previous

\footnotetext{
${ }^{17}$ When we add additional explanatory dummies for self-mentions that are higher than three mentions, four mentions and five mentions (the entrepreneur is mentioned at least 4 or 5 times, respectively), the results of the three-mentions variable remain significant. When we estimate the regression using at least four mentions or five mentions as the explanatory variable rather than three mentions, the interpretation of the results remains unchanged. When we used one or two mentions as the explanatory variable in our estimation, these variables were not statistically significant. It is reasonable that an entrepreneur might mention him or herself once or twice in the text without overshadowing the project, but three times unmistakably highlights the creator of the project.
} 
successes of the entrepreneur contributes to the number of backers and the sum pledged relative to the goal, but it does not significantly affect the likelihood of success. Surprisingly, basing the project in the US only reduces the likelihood that a project will reach its funding goal, and featuring a video is significantly positively correlated with all measures of success. We repeated the same exercise, while using mentioning the name in the header (Appendix B). Our conclusions remain the same. In the three panels of Table 6, we emphasize the difference between the maincategories by estimating the regression for each of the three success measures separately on the artistic and the technological main-categories. Clearly, when we separate the sample, the number of mentions only has a significant effect on the success of artistic projects. The coefficient on artistic projects is significantly positive for all three measures, while the coefficient of the technological projects is significant just for the number of backers - but weakly $(p=0.094)$. Moreover, the results are confirmed while estimating multinomial regressions, in which the dependent success variable receives 0 for failure, 1 for success (reaching 100\%-110\% of the goal), and 2 for overachievement. Again, we observed that the number of mentions was significant for the artistic categories but not for the technological ones.

\section{[Table 6]}

This finding might suggest that backers in technology-related projects are less sensitive to the entrepreneur's background. Our suggestion is that it might be easier to replace the entrepreneur in a promising technology-based project than in an artistic project due to the different nature of these projects. 
For robustness, we estimated an additional set of regressions to examine the effect of substantial self-mentioning. The results indicate that when entrepreneurs mention themselves more than 3 or 4 times, controlling for all other parameters, this has a significantly positive effect on success. When we jointly included several dummy variables for the different levels of mentioning in the regression (at least 3 mentions, at least 4 mentions, at least 5 mentions, etc.), the results indicated that the variable for more than five self-mentions does not significantly improve the likelihood of success beyond that conveyed by fewer mentions.

\section{Robustness Tests}

Several robustness tests were conducted to further test our results. We wanted to verify that our results are not substantially influenced by a large number of small projects that could be driven by emotional actions. We therefore selected a subsample consisting of the top decile of projects in terms of goals set, which necessitate substantial time and effort on the part of the entrepreneur. We estimated the same multivariate regression that we previously estimated using the sub-sample. All main coefficients retained their signs and significance. We repeated the same excursive focusing only on the film and video category. Again, our conclusions remained consistent.

Additionally, one may ask whether mentions capture omitted variables such as the reputation of the entrepreneur. To address this, we also conducted the above estimation for the bottom decile of projects (lowest goals). We assume that 
entrepreneurs with reputations, external to Kickstarter, would not initiate a project with a low goal. Again, all main coefficients retained their signs and significance. We conducted an additional test intended to address the concern that self-mentioning is highly correlated with the entrepreneur's reputation (outside of Kickstarter). We hand collected social network data on 500 entrepreneurs (who typically cite their twitter and/or Facebook page on their 'About' page). We randomly selected 500 business pitches that cited a social network ID and were representative of the self-mentions range. As well-known entrepreneurs generally have a large number of followers, we assessed whether there was a correlation between the scope of their social networks and their self-mention count in our dataset. We did not find any correlation between social network followers and self-mentions. A positive correlation would have suggested that well-known entrepreneurs mention themselves more, while a negative correlation would have indicated that it is sufficient for a very famous entrepreneur to present her picture, video or mention herself in the title only. In addition, the number of followers was not significantly different for entrepreneurs that mentioned their names in the header compared to those that did not.

Next, we wanted to further test the causality of the focus on the entrepreneur (via the use of mentions) as a facilitator of a positive reaction (trust and familiarity) toward the campaign. To test that, we sampled eight projects from the Film \& Video category in our database. We randomly selected four projects out of the group of projects in which the entrepreneur was mentioned substantially (average mentions of this group is 6.75), and four in which their respective founders were not mentioned at all. We 
then surveyed 31 students and graduates of Master and/or $\mathrm{PhD}$ programs of Economics and/or Business Administration, during July and August 2017. Each respondent was presented with five random texts of the eight projects sample and was asked to read them, and answer related questions. Specifically, the respondents were asked to rate on a Likert scale of 1 to 7 their trust of the entrepreneur to be devoted to the project, their trust of the entrepreneur to complete the project and how knowledgeable they feel about the entrepreneur. It is important to note that the subjects were not familiar with these projects or with the entrepreneurs prior to our survey. Hence, we can assume that their perception is only driven from reading the text of the pitch (including the self-mentions), and not from any other factors. The results were consistent: for all the questions the projects whose entrepreneur mentioned herself heavily were rated significantly higher. This was true for using parametric and non-parametric tests.

\section{CONCLUSION}

In this paper, we focus on one of the most challenging tasks for any entrepreneur: securing the initial financing for her early stage venture. An entrepreneurial pitch is the typical means of presenting the venture to potential investors / backers; in this pitch, the entrepreneur can decide the extent to which she will present herself, versus presenting the project idea. This choice can be critical to successfully securing financing and the potential execution of the project. We use Kickstarter, a leading crowdfunding platform, to investigate this dilemma. It provides us unique access to a 
broad range of early stage ventures with substantial details on the financing processes, including the full pitch provided by the entrepreneurs to the potential backers, and the projects' financing outcomes. Using a mention counting technique verified by human coding, we analyzed a variety (in 13 different categories, ranging from the technological to the artistic) of over 20,000 cross-vertical fundraising campaigns, which have collectively raised over $\$ 120 \mathrm{M}$.

Our findings indicate that entrepreneurs of artistic projects focus their pitch relatively more on themselves, and mentions their name more frequently on their Kickstarter page, compared with the entrepreneurs of technology projects. We also find that the name mentions are positively and statistically significantly associated with the success of the campaign for the projects, as well with the level of success (how much was raised compared to the goal). Separating the sample for technology and art projects, we find a significant effect of the number of mentions on success only for the latter. Our results remain consistent when we assess the projects with the largest goals, which receive more effort and planning on the part of the entrepreneurs. They are also consistent when considering the project with the lowest goals, suggesting that it is not the entrepreneur's outside reputation that is driving our results. This was also verified by controlling for the extent of the social networks of a random set of entrepreneurs. We conducted an additional test that examined how subjects estimate their level of: (1) trust of the entrepreneur to be devoted to the project; (2) trust of the entrepreneur to complete the project, and (3) how knowledgeable they feel about the entrepreneur after reading pitches from our sample. The experiment results were 
consistent with the conjecture that highlighting the entrepreneur by substantially mentioning his/her name, may increase trust and familiarity for potential backers. As there is growing interest in the academic literature regarding trust and familiarity and economic outcomes, we leave this for future research to explore further these conjectures.

We contribute to the investigation of pre-seed financing and Kickstarter as a leading crowdfunding platform. In the academic literature, there is relatively little information on pre-seed financing campaigns due to data gathering complexity. Using an online crowdfunding platform enables us to shed some light on this stage. Our research contributes to the understanding of reward-based crowdfunding platforms. Given the unique nature of reward-based crowdfunding, one may be concerned with the ability to generalize the results outside of this arena. While our results concern a specific type of market, we investigate the leading market of this type and the use of this mechanism is on the rise. Furthermore, our methodology, and some of the results, is relevant to other crowdfunding mechanisms, which employ similar fundraising techniques and target numerous potential small contributors.

We also contribute to the ongoing vocal discussion amongst early stage investors on whether the focus in evaluating a new investment should be on the horse (the venture) or the jockey (the entrepreneur). While this debate received substantial attention among VC investors and researchers (e.g. Kaplan, Sensoy, and Stromberg (2009)), the debate regarding the importance of the idea, versus the human capital, is also relevant to pre-seed financing of different ventures where friends and family, angels 
and wealthy individuals make the decision whether to invest in a venture or not. Given the growing use of crowdfunding to finance new projects, it should be of interest to investigate this question with respect to reward and not only equity. We leave for future research the investigation of this question with relation to other type of crowdfunding platforms such as charity and $\mathrm{P} 2 \mathrm{P}$ lending.

Our paper is also closely related to the recent emerging literature that investigates the text provided by entrepreneurs in the crowdfunding pitch. The related literature focused on the style, or narrative (e.g Parhankangas and Renko (2017), Manning and Bejarano (2016), Allison et al (2015)). While our approach is very different as we focus on the number of mentions of the entrepreneur name, we leave for future research the investigation of the relations of style and narrative to our measure and to different measures of trust.

\section{ACKNOWLEDGEMENTS}

We have benefited from comments by Guillaume Andrieu, Alon Eizenberg, Niron Hashai, Enrichetta Ravina, Robert Whitelaw, Yishay Yafeh, José Yagüe, Roy Zuckerman, the referees and the editor. We further thank the 2016 American Economic Association meeting (San Francisco, CA), 2014 Strategic Management Society meeting (Tel-Aviv, Israel), 2014 Association of Financial Economists meeting (Philadelphia, PA), the 2013 CEPR First European Workshop on Entrepreneurship Economics (Amsterdam), the XXI Finance Forum (Segovia, Spain) and the 2013 Leeds \& Kauffman crowdfunding conference (Boulder, CO), 
and seminar participants at Ben-Gurion University, BI (Oslo), NYU Shanghai and the Hebrew University of Jerusalem. The project received the 2014 Coller Institute of Venture's (CIV) senior research award, and financial support from the Asper Center and the Kruger Center at the Hebrew University. Sade thanks the Israel Science Foundation (ISF 430/14). We would like to thank Talia Ochayon for her excellent research assistance.

\section{REFERENCES}

Agrawal, A., Catalini, C. and Goldfarb, A., 2015. Friends, family, and the flat world: The geography of crowdfunding. Journal of Economics \& Management Strategy, Volume 24, Number 2, Summer 2015, 253-274

Allison, T. H., Davis, B. C., Short, J. C. and Webb, J. W. 2015, Crowdfunding in a Prosocial Microlending Environment: Examining the Role of Intrinsic Versus Extrinsic Cues. Entrepreneurship Theory and Practice, 39: 53-73

Bernstein, S., Korteweg, A. and Laws, K., 2017. Attracting Early-Stage Investors: Evidence from a Randomized Field Experiment. The Journal of Finance, 72(2), pp.509-538.

Bradford, C.S., 2012. Crowdfunding and the federal securities laws.

Cardon, M.S., Sudek, R. and Mitteness, C., 2009. The impact of perceived entrepreneurial passion on angel investing. Frontiers of entrepreneurship research, 29(2), p.1.

Chen, X.P., Yao, X. and Kotha, S., 2009. Entrepreneur passion and preparedness in business plan presentations: a persuasion analysis of venture capitalists' funding decisions. Academy of Management journal, 52(1), pp.199-214.

Conti, A., Thursby, M. and Rothaermel, F.T., 2013. Show Me the Right Stuff: Signals for High-Tech Startups. Journal of Economics \& Management Strategy, 22(2), pp.341-364.

Duarte, J., Siegel, S. and Young, L., 2012. Trust and credit: the role of appearance in peer-to-peer lending. The Review of Financial Studies, 25(8), pp.2455-2484. 
Dushnitsky, G., Guerini, M., Piva, E. and Rossi-Lamastra, C., 2016. Crowdfunding in Europe: determinants of platform creation across countries. California management review, 58(2), pp.44-71.

Eesley, C.E. and Roberts, E.B., 2012. Are you experienced or are you talented?: When does innate talent versus experience explain entrepreneurial performance? Strategic Entrepreneurship Journal, 6(3), pp.207-219.

Gompers, P., Kovner, A., Lerner, J. and Scharfstein, D., 2010. Performance persistence in entrepreneurship. Journal of Financial Economics, 96(1), pp.18-32.

Hsu, D.H., 2007. Experienced entrepreneurial founders, organizational capital, and venture capital funding. Research Policy, 36(5), pp.722-741.

Kahneman, D., 1973. Attention and effort (Vol. 1063). Englewood Cliffs, NJ: Prentice-Hall.

Kaplan, S.N., Sensoy, B.A. and Strömberg, P., 2009. Should investors bet on the jockey or the horse? Evidence from the evolution of firms from early business plans to public companies. The Journal of Finance, 64(1), pp.75-115.

Lambert, T. and Schwienbacher, A., 2010. An empirical analysis of crowdfunding. Social Science Research Network, 1578175, pp.1-23.

Manning S and Bejarano T, 2016. Convincing the crowd: Entrepreneurial storytelling in crowdfunding campaigns. Strategic Organization, 15:2, 194-219

Marom, D., 2012. Evolution of Firms - Evidence from Israeli Start-ups.

Massolution, C.L., 2015. Crowdfunding industry report.

Mollick, E., 2014. The dynamics of crowdfunding: An exploratory study. Journal of business venturing, 29(1), pp.1-16.

Packalen, K.A., 2007. Complementing capital: The role of status, demographic features, and social capital in founding teams' abilities to obtain resources. Entrepreneurship Theory and Practice, 31(6), pp.873-891.

Paik, Y., 2014. Serial entrepreneurs and venture survival: Evidence from US venturecapital-financed semiconductor firms. Strategic Entrepreneurship Journal, 8(3), pp.254-268.

Parhankangas, A., and Renko M., 2017, Linguistic style and crowdfunding success among social and commercial entrepreneurs, Journal of Business Venturing, Volume 32, Issue 2, Pages 215-236

Penrose, E. (1959), The Theory of the Growth of the Firm, Oxford university press. 
Rajan, R.G., 2012. Presidential address: The corporation in finance. The Journal of Finance, 67(4), pp.1173-1217.

Rajan, R.G. and Zingales, L., 2001. The firm as a dedicated hierarchy: A theory of the origins and growth of firms. The Quarterly Journal of Economics, 116(3), pp.805.

Ravina, E., 2012. Love \& loans: The effect of beauty and personal characteristics in credit markets.

Schwienbacher, A. and Larralde, B., 2010. Crowdfunding of small entrepreneurial ventures. Handbook of Entrepreneurial Finance, Oxford University Press.

Wasserman, N., Nohria, N. and Anand, B.N., 2001. When does leadership matter? The contingent opportunities view of CEO leadership.

Zhang, J., 2011. The advantage of experienced start-up founders in venture capital acquisition: evidence from serial entrepreneurs. Small Business Economics, 36(2). 
Table 1

Descriptive Statistics: Projects, Goals, and Sums Pledged, by Category

Descriptive statistics on sub-categories and main-categories regarding the number of projects, the average goal set per project, the sum of the goals set by all projects in the category, the average amount of money pledged per project, and the sum of the total amount pledged, all divided by category.

\begin{tabular}{|c|c|c|c|c|c|c|c|c|}
\hline Category & Projects & Pct. & $\begin{array}{l}\text { Goal per } \\
\text { Project }\end{array}$ & $\begin{array}{c}\text { Sum of } \\
\text { Goal }\end{array}$ & Pct. & $\begin{array}{l}\text { Pledged } \\
\text { per } \\
\text { Project }\end{array}$ & $\begin{array}{c}\text { Total } \\
\text { Pledged }\end{array}$ & Pct. \\
\hline Art & 1,728 & $8.5 \%$ & $4,851.6$ & $8,383,641$ & $5.5 \%$ & $3,751.8$ & $6,483,062$ & $5.3 \%$ \\
\hline Comics & 533 & $2.6 \%$ & $4,304.7$ & $2,294,406$ & $1.9 \%$ & $7,064.2$ & $3,765,226$ & $3.1 \%$ \\
\hline Dance & 490 & $2.4 \%$ & $3,302.5$ & $1,618,217$ & $1.5 \%$ & $3,109.3$ & $1,523,576$ & $1.3 \%$ \\
\hline Fashion & 381 & $1.9 \%$ & $5,321.0$ & $2,027,320$ & $1.3 \%$ & $4,433.7$ & $1,689,226$ & $1.4 \%$ \\
\hline $\begin{array}{l}\text { Film \& } \\
\text { Video }\end{array}$ & 5,737 & $\begin{array}{c}28.4 \\
\%\end{array}$ & $10,977.7$ & $62,979,112$ & 40.9 & $\begin{array}{l}6,925 \\
766.9\end{array}$ & $38,821,788$ & $31.9 \%$ \\
\hline Food & 581 & $2.9 \%$ & $10,338.4$ & $6,006,623$ & 3.9 & $7,442.4$ & $4,324,043$ & $3.5 \%$ \\
\hline Music & 5,132 & $\begin{array}{c}25.4 \\
\%\end{array}$ & $4,291.9$ & $22,026,216$ & 14.3 & $4,535.4$ & $23,275,832$ & $19.1 \%$ \\
\hline Photography & 760 & $3.8 \%$ & $4,624.5$ & $3,514,590$ & 2.3 & $3,986.1$ & $3,029,404$ & $2.5 \%$ \\
\hline Publishing & 1,627 & $8.0 \%$ & $5,144.7$ & $8,370.409$ & $5.4 \%$ & $4,070.8$ & $6,623,150$ & $5.4 \%$ \\
\hline Theater & 1,612 & $8.0 \%$ & $3,937.8$ & $6,347,704$ & $4.1 \%$ & $3,680.9$ & $5,933,620$ & $4.9 \%$ \\
\hline $\begin{array}{c}\text { Total of } \\
\text { artistic } \\
\text { categories }\end{array}$ & 19,001 & $\begin{array}{c}91.9 \\
\%\end{array}$ & $6,650.2$ & $\begin{array}{c}115,197,82 \\
9\end{array}$ & $\begin{array}{c}80.3 \\
\%\end{array}$ & $5,137.9$ & $95,468,927$ & $78.3 \%$ \\
\hline Games & 584 & $2.8 \%$ & $43,910.2$ & $25,643,556$ & $\begin{array}{c}15.4 \\
\%\end{array}$ & $8,407.5$ & $4,909,963$ & $4.0 \%$ \\
\hline $\begin{array}{l}\text { Total of } \\
\text { gaming } \\
\text { category }\end{array}$ & 584 & $2.9 \%$ & $43,910.2$ & $25,643,556$ & $\begin{array}{c}15.4 \\
\%\end{array}$ & $8,407.5$ & $4,909,963$ & $4.0 \%$ \\
\hline Design & 739 & $3.7 \%$ & $12,078.3$ & $8,925,840$ & $5.4 \%$ & $20,738.9$ & $15,326,014$ & $12.6 \%$ \\
\hline Technology & 320 & $1.6 \%$ & $14,419.7$ & $4,614,315$ & $2.8 \%$ & $19,268.0$ & $6,165,759$ & $45.1 \%$ \\
\hline $\begin{array}{c}\text { Total of } \\
\text { technological } \\
\text { categories }\end{array}$ & 1,059 & $5.2 \%$ & $12,785.8$ & $13,540,155$ & $8.2 \%$ & $20,294.4$ & $21,491,773$ & $17.6 \%$ \\
\hline
\end{tabular}


Table 2

The Three Mentioning Measures for the Business Pitches

Table 2 reports basic descriptive statistics for the three mentioning measures as applied to three different levels: the full sample, the successful projects sample, and the failed projects sample. For each, the number of observations, mean number of mentions, standard deviation, median, and $90 \%$ of the sample are provided.

\begin{tabular}{lrrrrr}
\hline & Obs. & Mean & Std Dev. & Median & $90 \%$ \\
\hline All of the 'About' Section & & & & & \\
Number of mentions & 20,224 & 0.714 & 1.409 & 0 & 2 \\
Number of mentions for successful projects & 16,111 & 0.769 & 1.447 & 0 & 2 \\
Number of mentions for failed projects & 4,113 & 0.501 & 1.227 & 0 & 1 \\
\hline First 100 words of the 'About' Section & & & & & \\
Number of mentions & 20,224 & 0.282 & 0.605 & 0 & 1 \\
Number of mentions for successful projects & 16,111 & 0.305 & 0.624 & 0 & 1 \\
Number of mentions for failed projects & 4,113 & 0.192 & 0.513 & 0 & 1 \\
\hline Project Title & & & & & \\
A Mention in the Title & 20,224 & 0.176 & 0.381 & 0 & 1 \\
A mention for successful projects & 16,111 & 0.199 & 0.400 & 0 & 1 \\
A Mention failed projects & 4,113 & 0.083 & 0.276 & 0 & 0 \\
\hline
\end{tabular}


Table 3

\section{Multivariate Analysis - Drivers of Self-Mentioning}

This table reports three regression methods - OLS, Poisson and Tobit. The dependent variable in all regressions is the Number of Mentions. The results were consistent across all regressions.

\begin{tabular}{|c|c|c|c|c|c|c|c|c|c|c|c|c|c|}
\hline & & & & & & & & & & Poisson 1 & ggression & Tobit $R$ & ression \\
\hline & $\begin{array}{c}\text { About } \\
\text { Section } \\
\end{array}$ & $\begin{array}{c}\text { First 10O } \\
\text { Words }\end{array}$ & Title & $\begin{array}{c}\text { About } \\
\text { Section }\end{array}$ & $\begin{array}{c}\text { First } 100 \\
\text { Words }\end{array}$ & Title & $\begin{array}{c}\text { About } \\
\text { Section }\end{array}$ & $\begin{array}{c}\text { First 10O } \\
\text { Words }\end{array}$ & Title & $\begin{array}{l}\text { About } \\
\text { Section } \\
\end{array}$ & $\begin{array}{c}\text { First 10O } \\
\text { Words }\end{array}$ & $\begin{array}{c}\text { About } \\
\text { Section } \\
\end{array}$ & $\begin{array}{c}\text { First } 100 \\
\text { Words } \\
\end{array}$ \\
\hline Technological Main-Category & $\begin{array}{c}- \\
0.309^{* * * *} \\
(0.044)\end{array}$ & $\begin{array}{c}-0.118^{* * * *} \\
(0.019)\end{array}$ & $\begin{array}{c}-0.799^{* * *} \\
(0.068)\end{array}$ & $\begin{array}{c}- \\
0.307^{* * * *} \\
(0.044)\end{array}$ & $\begin{array}{c}-0.117^{* * *} \\
(0.019)\end{array}$ & $\begin{array}{c}-0.799^{* * *} \\
(0.068)\end{array}$ & $\begin{array}{c}- \\
0.308^{* * *} \\
(0.044)\end{array}$ & $\begin{array}{c}-0.117^{* * * *} \\
(0.019)\end{array}$ & $\begin{array}{c}- \\
0.798^{* * *} \\
(0.068)\end{array}$ & $\begin{array}{c}- \\
0.496^{* * *} \\
(0 / 044)\end{array}$ & $\begin{array}{c}- \\
0.526^{* * *} \\
(0.076)\end{array}$ & $\begin{array}{c}-1.252^{* * * *} \\
(0.115)\end{array}$ & $\begin{array}{c}-0.761^{* * *} \\
(0.093)\end{array}$ \\
\hline Log (Goal) & $\begin{array}{c}0.059^{* * * *} \\
(0.009)\end{array}$ & $\begin{array}{c}-0.013^{* * * *} \\
(0.004)\end{array}$ & $\begin{array}{c}0.061^{* * * *} \\
(0.009)\end{array}$ & $\begin{array}{c}0.052^{* * * *} \\
(0.009)\end{array}$ & $\begin{array}{l}0.009^{* * *} \\
(0.004)\end{array}$ & $\begin{array}{c}0.059^{* * * *} \\
(0.009)\end{array}$ & $\begin{array}{l}0.052^{* * * *} \\
(0.009)\end{array}$ & $\begin{array}{l}0.008^{* * *} \\
(0.004)\end{array}$ & $\begin{array}{c}0.056^{* * * *} \\
(0.009)\end{array}$ & $\begin{array}{l}0.072^{* * * *} \\
(0.008)\end{array}$ & $\begin{array}{c}0.043^{* * * *} \\
(0.011)\end{array}$ & $\begin{array}{c}0.146^{* * * *} \\
(0.021)\end{array}$ & $\begin{array}{c}0.056^{* * * *} \\
(0.016)\end{array}$ \\
\hline Previous Successes of Entrepreneur & $\begin{array}{c}0.147^{* * * *} \\
(0.018)\end{array}$ & $\begin{array}{c}0.109^{* * * *} \\
(0.008)\end{array}$ & $\begin{array}{l}0.035^{*} \\
(0.018)\end{array}$ & & & & & & & $\begin{array}{l}0.124^{* * * *} \\
(0.009)\end{array}$ & $\begin{array}{c}0.159^{* * * *} \\
(0.011)\end{array}$ & $\begin{array}{c}0.272^{* * *} \\
(0.038)\end{array}$ & $\begin{array}{c}0.212^{* * * *} \\
(0.028)\end{array}$ \\
\hline Success in Last Project Dummy & & & & $\begin{array}{c}0.172^{* * *} \\
(0.065)\end{array}$ & $\begin{array}{l}0.115^{* * *} \\
(0.029)\end{array}$ & $\begin{array}{l}-0.123^{*} \\
(0.075)\end{array}$ & & & & & & & \\
\hline Kickstarter Experience Dummy & & & & & & & $\begin{array}{c}0.072 \\
(0.047)\end{array}$ & $\begin{array}{c}0.034 \\
(0.021)\end{array}$ & $\begin{array}{c}- \\
0.248^{* * * *} \\
(0.057)\end{array}$ & & & & \\
\hline Video & $\begin{array}{c}0.109^{* * * *} \\
(0.026)\end{array}$ & $\begin{array}{c}0.057^{* * * *} \\
(0.011)\end{array}$ & $\begin{array}{c}0.155^{* * *} \\
(0.028)\end{array}$ & $\begin{array}{c}0.108^{* * * *} \\
(0.026)\end{array}$ & $\begin{array}{c}0.056^{* * * *} \\
(0.011)\end{array}$ & $\begin{array}{c}0.154^{* * * *} \\
(0.028)\end{array}$ & $\begin{array}{c}0.108^{* * * *} \\
(0.026)\end{array}$ & $\begin{array}{c}0.056^{* * * *} \\
(0.011)\end{array}$ & $\begin{array}{c}0.153^{* * * *} \\
(0.028)\end{array}$ & $\begin{array}{l}0.154^{* * * *} \\
(0.023)\end{array}$ & $\begin{array}{l}0.201^{* * * *} \\
(0.035)\end{array}$ & $\begin{array}{c}0.248^{* * *} \\
(0.062)\end{array}$ & $\begin{array}{c}0.248^{* * * *} \\
(0.048)\end{array}$ \\
\hline Log (Total Words in the About Section) & $\begin{array}{c}0.304^{* * * *} \\
(0.014)\end{array}$ & & & $\begin{array}{c}0.307^{* * * *} \\
(0.014)\end{array}$ & & & $\begin{array}{l}0.307^{* * * *} \\
(0.014)\end{array}$ & & & $\begin{array}{c}0.482^{* * * *} \\
(0.014)\end{array}$ & & $\begin{array}{c}0.819^{* * * *} \\
(0.037)\end{array}$ & \\
\hline $\begin{array}{l}\text { Available Links to Websites by the } \\
\text { Entrepreneur }\end{array}$ & $\begin{array}{l}-0.036 \\
(0.025)\end{array}$ & $\begin{array}{l}-0.011 \\
(0.011)\end{array}$ & $\begin{array}{c}- \\
0.083^{* * * *} \\
(0.028)\end{array}$ & $\begin{array}{l}-0.023 \\
(0.025)\end{array}$ & $\begin{array}{l}0.000 \\
(0.011)\end{array}$ & $\begin{array}{c}- \\
0.074^{* * * *} \\
(0.028)\end{array}$ & $\begin{array}{l}-0.021 \\
(0.025)\end{array}$ & $\begin{array}{c}0.002 \\
(0.011)\end{array}$ & $\begin{array}{l}-0.063^{* * *} \\
(0.028)\end{array}$ & $\begin{array}{l}-0.044^{* *} \\
(0.022)\end{array}$ & $\begin{array}{c}-0.021 \\
(0.035)\end{array}$ & $\begin{array}{l}-0.114^{*} \\
(0.061)\end{array}$ & $\begin{array}{l}-0.029 \\
(0.047)\end{array}$ \\
\hline US Based Project & $\begin{array}{c}0.148^{* * * *} \\
(0.043)\end{array}$ & $\begin{array}{c}0.097^{* * * *} \\
(0.019)\end{array}$ & $\begin{array}{c}0.537^{* * * *} \\
(0.057)\end{array}$ & $\begin{array}{c}0.148^{* * * *} \\
(0.043)\end{array}$ & $\begin{array}{c}0.097^{* * * *} \\
(0.019)\end{array}$ & $\begin{array}{c}0.536^{* * * *} \\
(0.057)\end{array}$ & $\begin{array}{c}0.147^{* * * *} \\
(0.043)\end{array}$ & $\begin{array}{c}0.096^{* * * *} \\
(0.019)\end{array}$ & $\begin{array}{c}0.537^{* * *} \\
(0.057)\end{array}$ & $\begin{array}{c}0.218^{* * * *} \\
(0.039)\end{array}$ & $\begin{array}{c}0.398^{* * * *} \\
(0.070)\end{array}$ & $\begin{array}{c}0.528^{* * * *} \\
(0.105)\end{array}$ & $\begin{array}{c}0.492^{* * * *} \\
(0.086)\end{array}$ \\
\hline Constant & $\begin{array}{c}-1.568^{* * *} \\
(0.103)\end{array}$ & $\begin{array}{c}0.122^{* * * *} \\
(0.035)\end{array}$ & $\begin{array}{c}-1.780^{* * *} \\
(0.094)\end{array}$ & $\begin{array}{c}-1.533^{* * *} \\
(0.104)\end{array}$ & $\begin{array}{c}0.157^{* * * *} \\
(0.035)\end{array}$ & $\begin{array}{c}-1.755^{* * *} \\
(0.094)\end{array}$ & $\begin{array}{c}-1.531^{* * *} \\
(0.104)\end{array}$ & $\begin{array}{c}0.160^{* * * *} \\
(0.035)\end{array}$ & $\begin{array}{c}-1.735^{* * *} \\
(0.094)\end{array}$ & $\begin{array}{c}-3.847^{* * *} \\
(0.097)\end{array}$ & $\begin{array}{c}-1.866^{* * *} \\
(0.116)\end{array}$ & $\begin{array}{c}-7.072^{* * *} \\
(0.265)\end{array}$ & $\begin{array}{c}-2.120^{* * * *} \\
(0.154)\end{array}$ \\
\hline Observations & 19,737 & 19,639 & 19,639 & 19,737 & 19,639 & 19,639 & 19,737 & 19,639 & 19,639 & 19,637 & 19,639 & 19,637 & 19,639 \\
\hline R-Squared / Pseudo R-Squared & 0.034 & 0.015 & 0.021 & 0.031 & 0.006 & 0.021 & 0.031 & 0.005 & 0.022 & 0.036 & 0.010 & 0.016 & 0.007 \\
\hline
\end{tabular}




\section{Table 4}

\section{Measures of Success by Category}

This table reports the means of goals, success, and outcome of the projects across the platforms' categories and the three main-categories.

\begin{tabular}{lccccc}
\hline & $\begin{array}{c}\text { Mean of } \\
\% \text { of } \\
\text { Category }\end{array}$ & $\begin{array}{c}\text { Mean of } \\
\text { Goal }\end{array}$ & $\begin{array}{c}\text { Mean of } \% \\
\text { Pledged }\end{array}$ & $\begin{array}{c}\text { Mean of } \\
\text { Backers }\end{array}$ & Freq. \\
\hline Art & 0.823 & $4,851.6$ & 1.602 & 58.8 & 1,728 \\
Comics & 0.799 & $4,304.7$ & 3.524 & 128.7 & 533 \\
Dance & 0.882 & $3,302.5$ & 1.289 & 45.2 & 490 \\
Fashion & 0.696 & $5,321.0$ & 2.525 & 56.8 & 381 \\
Film \& Video & 0.753 & $10,977.7$ & 3.790 & 76.5 & 5,737 \\
Food & 0.773 & $10,338.4$ & 1.050 & 92.7 & 581 \\
Music & 0.883 & $4,291.9$ & 1.821 & 67.4 & 5,132 \\
Photography & 0.778 & $4,624.5$ & 1.100 & 54.6 & 760 \\
Publishing & 0.719 & $5,144.7$ & 2.096 & 68.6 & 1,627 \\
Theater & 0.898 & $3,937.8$ & 1.817 & 50.4 & 1,612 \\
Total of artistic categories & 0.810 & $6,650.2$ & 2.428 & 69.2 & 18,581 \\
\hline & & & & & \\
Games & 0.658 & $43,910.2$ & 1.769 & 182.5 & 584 \\
Total of gaming category & 0.658 & $43,910.2$ & 1.769 & 182.5 & 584 \\
\hline & & & & & \\
Design & 0.652 & $12,078.3$ & 6.136 & 287.7 & 739 \\
Technology & 0.603 & $14,419.7$ & 1.648 & 213.6 & 320 \\
Total of technological categories & 0.637 & $12,785.8$ & 4.780 & 265.3 & 1,059 \\
\hline
\end{tabular}




\section{Table 5}

\section{Effects of the Project Presentation Variables on Fundraising Success}

This table presents the OLS Regression Results for the Effects of Antecedents on Funding Measures. The dependent variables are reaching the funding goal, \% pledged and \# of backers, and the independent variables are the entrepreneurial presentation measures (different measures of self-mentions, video and links) and project attributes (goal, main category and location).

\begin{tabular}{|c|c|c|c|}
\hline & $\begin{array}{l}\text { Reaching } \\
\text { The Goal }\end{array}$ & $\%$ Pledged & $\begin{array}{c}\text { \# of } \\
\text { Backers }\end{array}$ \\
\hline \multirow[t]{2}{*}{ Technological Main-Category } & $-0.364^{* * *}$ & $-0.115^{* * *}$ & $0.375^{* * *}$ \\
\hline & $(0.043)$ & $(0.041)$ & $(0.037)$ \\
\hline \multirow[t]{2}{*}{ More than Two Mentions } & $0.393^{* * *}$ & $0.166^{* * *}$ & $0.274^{* * *}$ \\
\hline & $(0.050)$ & (0.036) & (0.033) \\
\hline \multirow[t]{2}{*}{$\log ($ Goal $)$} & $-0.217^{* * *}$ & & \\
\hline & $(0.010)$ & & \\
\hline \multirow[t]{2}{*}{ Previous Successes of Entrepreneur } & -0.007 & $0.120^{* * *}$ & $-0.040^{* * *}$ \\
\hline & $(0.020)$ & $(0.017)$ & $(0.015)$ \\
\hline \multirow[t]{2}{*}{ Video on The Project Page } & $0.358^{* * *}$ & $0.327^{* * *}$ & $0.182^{* * *}$ \\
\hline & (0.028) & (0.024) & $(0.022)$ \\
\hline \multirow[t]{2}{*}{ Log(Total Words in the About Section) } & $0.182^{* * *}$ & $0.069^{* * *}$ & $0.346^{* * *}$ \\
\hline & $(0.016)$ & $(0.013)$ & $(0.012)$ \\
\hline \multirow[t]{2}{*}{ Available Links to Websites by the Entrepreneur } & $-0.538^{* * *}$ & $-0.316^{* * *}$ & $-0.141^{* * *}$ \\
\hline & $(0.026)$ & (0.024) & $(0.022)$ \\
\hline \multirow[t]{2}{*}{ US Based Project } & $-0.126^{* *}$ & -0.048 & $-0.114^{* * *}$ \\
\hline & (o.049) & $(0.040)$ & (o.036) \\
\hline \multirow[t]{2}{*}{ Constant } & $2.215^{* * *}$ & $-0.318^{* * *}$ & $1.703^{* * *}$ \\
\hline & $(0.116)$ & (o.o88) & $(0.079)$ \\
\hline Observations & 19,637 & 19,215 & 19,216 \\
\hline R-squared / Pseudo R-Squared & 0.122 & 0.052 & 0.063 \\
\hline
\end{tabular}




\begin{tabular}{|c|c|c|c|}
\hline & $\begin{array}{l}\text { Reaching } \\
\text { The Goal }\end{array}$ & $\begin{array}{c}\% \\
\text { Pledged }\end{array}$ & $\begin{array}{c}\text { \# of } \\
\text { Backers }\end{array}$ \\
\hline \multirow[t]{2}{*}{ Technological Main-Category } & $-0.341^{* * *}$ & $-0.11^{* * *}$ & $0.389^{* * *}$ \\
\hline & $(0.044)$ & $(0.041)$ & (o.037) \\
\hline \multirow[t]{2}{*}{ Number of Mentions } & $0.099^{* * *}$ & $0.044^{* * *}$ & $0.068^{* * *}$ \\
\hline & (0.009) & $(0.007)$ & (0.006) \\
\hline \multirow[t]{2}{*}{$\log ($ Goal) } & $-0.219^{* * *}$ & & \\
\hline & $(0.010)$ & & \\
\hline \multirow[t]{2}{*}{ Previous Successes of Entrepreneur } & -0.011 & $0.118 * * *$ & $-0.042^{* * *}$ \\
\hline & $(0.020)$ & $(0.017)$ & $(0.015)$ \\
\hline \multirow[t]{2}{*}{ Video on The Project Page } & $0.356^{* * *}$ & $0.326^{* * *}$ & $0.183^{* * *}$ \\
\hline & $(0.028)$ & $(0.024)$ & $(0.022)$ \\
\hline \multirow[t]{2}{*}{ Log(Total Words in the About Section) } & $0.169^{* * *}$ & $0.062^{* * *}$ & $0.336^{* * *}$ \\
\hline & $(0.016)$ & (0.013) & $(0.012)$ \\
\hline \multirow[t]{2}{*}{ Available Links to Websites by the Entrepreneur } & $-0.539^{* * *}$ & $-0.315^{* * *}$ & $-0.140^{* * *}$ \\
\hline & $(0.027)$ & (0.024) & $(0.022)$ \\
\hline \multirow[t]{2}{*}{ US Based Project } & $-0.136^{* * *}$ & -0.052 & $-0.119^{* * *}$ \\
\hline & (0.049) & $(0.040)$ & $(0.036)$ \\
\hline \multirow[t]{2}{*}{ Constant } & $2.276^{* * *}$ & $-0.296^{* * *}$ & $1.735^{* * *}$ \\
\hline & $(0.116)$ & (0.088) & (o.079) \\
\hline Observations & 19,637 & 19,215 & 19,216 \\
\hline R2 / Pseudo R2 & 0.125 & 0.053 & 0.065 \\
\hline
\end{tabular}




\begin{tabular}{|c|c|c|c|}
\hline & $\begin{array}{c}\text { Reaching The } \\
\text { Goal }\end{array}$ & $\begin{array}{c}\% \\
\text { Pledged }\end{array}$ & $\begin{array}{c}\text { \# of } \\
\text { Backers }\end{array}$ \\
\hline Technological Main-Category & $\begin{array}{c}-0.317^{* * *} \\
(0.044)\end{array}$ & $\begin{array}{c}-0.084^{* *} \\
(0.041)\end{array}$ & $\begin{array}{c}0.409^{* * *} \\
(0.037)\end{array}$ \\
\hline One mention & $\begin{array}{c}0.266^{* * *} \\
(0.027)\end{array}$ & $\begin{array}{c}0.172^{* * *} \\
(0.022)\end{array}$ & $\begin{array}{c}0.186^{* * *} \\
(0.020)\end{array}$ \\
\hline Two mentions & $\begin{array}{c}0.357^{* * *} \\
(0.043)\end{array}$ & $\begin{array}{c}0.199^{* * *} \\
(0.034)\end{array}$ & $\begin{array}{c}0.226^{* * *} \\
(0.030)\end{array}$ \\
\hline Three mentions & $\begin{array}{c}0.531^{* * *} \\
(0.078)\end{array}$ & $\begin{array}{c}0.281^{* * *} \\
(0.055)\end{array}$ & $\begin{array}{c}0.294^{* * *} \\
(0.050)\end{array}$ \\
\hline Four mentions & $\begin{array}{c}0.422^{* * *} \\
(0.098)\end{array}$ & $\begin{array}{c}0.253^{* * *} \\
(0.074)\end{array}$ & $\begin{array}{c}0.437^{* * *} \\
(0.067)\end{array}$ \\
\hline Five mentions or more & $\begin{array}{c}0.838^{* * *} \\
(0.153)\end{array}$ & $\begin{array}{c}0.272^{* * *} \\
(0.095)\end{array}$ & $\begin{array}{c}0.439^{* * *} \\
(0.086)\end{array}$ \\
\hline $\log ($ Goal) & $\begin{array}{c}-0.221^{* * *} \\
(0.010)\end{array}$ & & \\
\hline Previous Successes of Entrepreneur & $\begin{array}{l}-0.018 \\
(0.021)\end{array}$ & $\begin{array}{c}0.116^{* * *} \\
(0.017)\end{array}$ & $\begin{array}{c}-0.045^{* * *} \\
(0.015)\end{array}$ \\
\hline Video on The Project Page & $\begin{array}{c}0.356^{* * *} \\
(0.028)\end{array}$ & $\begin{array}{c}0.326^{* * *} \\
(0.024)\end{array}$ & $\begin{array}{c}0.182^{* * *} \\
(0.022)\end{array}$ \\
\hline Log(Total Words in the About Section) & $\begin{array}{c}0.166^{* * *} \\
(0.016)\end{array}$ & $\begin{array}{c}0.058^{* * *} \\
(0.013)\end{array}$ & $\begin{array}{c}0.336^{* * *} \\
(0.012)\end{array}$ \\
\hline Available Links to Websites by the Entrepreneur & $\begin{array}{c}-0.539^{* * *} \\
(0.027)\end{array}$ & $\begin{array}{c}-0.312^{* * *} \\
(0.024)\end{array}$ & $\begin{array}{c}-0.138^{* * *} \\
(0.022)\end{array}$ \\
\hline US Based Project & $\begin{array}{c}-0.147^{* * *} \\
(0.049)\end{array}$ & $\begin{array}{c}-0.063 \\
(0.040)\end{array}$ & $\begin{array}{c}-0.130^{* * *} \\
(0.036)\end{array}$ \\
\hline Constant & $\begin{array}{c}2.273^{* * *} \\
(0.116)\end{array}$ & $\begin{array}{c}-0.302^{* * *} \\
(0.087)\end{array}$ & $\begin{array}{l}1.713^{* * *} \\
(0.079)\end{array}$ \\
\hline Observations & 19,637 & 19,215 & 19,216 \\
\hline R2 / Pseudo R2 & 0.1296 & 0.056 & 0.068 \\
\hline
\end{tabular}




\section{Table 6}

\section{Predictions of Project Success by Main-Categories}

This table presents the results of three OLS Regressions-dependent variables are the three success measures, while we compare the two main categories (artistic and technological) based on different pitch attributes.

\begin{tabular}{|c|c|c|c|c|c|c|}
\hline & \multicolumn{2}{|c|}{$\begin{array}{c}\text { Dependent Variable: } \\
\text { Success in Reaching the Goal }\end{array}$} & \multicolumn{2}{|c|}{$\begin{array}{l}\text { Dependent Variable: } \\
\text { Log of \% Pledged }\end{array}$} & \multicolumn{2}{|c|}{$\begin{array}{l}\text { Dependent Variable: } \\
\text { Log of Backers }\end{array}$} \\
\hline & Artistic & Technological & Artistic & Technological & Artistic & Technological \\
\hline More than Two Mentions & $\begin{array}{l}0.413^{* * *} \\
(0.052)\end{array}$ & $\begin{array}{c}0.167 \\
(0.179)\end{array}$ & $\begin{array}{l}0.164^{* * *} \\
(0.036)\end{array}$ & $\begin{array}{c}0.231 \\
(0.249)\end{array}$ & $\begin{array}{l}0.270^{* * *} \\
(0.033)\end{array}$ & $\begin{array}{l}0.371^{*} \\
(0.221)\end{array}$ \\
\hline Log (Goal) & $\begin{array}{l}-0.215^{* * *} \\
(0.010)\end{array}$ & $\begin{array}{l}-0.243^{* * *} \\
(0.034)\end{array}$ & & & & \\
\hline Previous Successes of Entrepreneur & $\begin{array}{l}-0.005 \\
(0.021)\end{array}$ & $\begin{array}{l}-0.038 \\
(0.078)\end{array}$ & $\begin{array}{l}0.123^{* * *} \\
(0.017)\end{array}$ & $\begin{array}{c}0.030 \\
(0.105)\end{array}$ & $\begin{array}{c}-0.036^{* *} \\
(0.015)\end{array}$ & $\begin{array}{l}-0.094 \\
(0.093)\end{array}$ \\
\hline Video on the Project Page & $\begin{array}{l}0.357^{* * *} \\
(0.028)\end{array}$ & $\begin{array}{l}0.374^{* * *} \\
(0.120)\end{array}$ & $\begin{array}{l}0.309^{* * *} \\
(0.024)\end{array}$ & $\begin{array}{l}0.712^{* * *} \\
(0.166)\end{array}$ & $\begin{array}{l}0.179^{* * *} \\
(0.022)\end{array}$ & $\begin{array}{l}0.244^{*} \\
(0.148)\end{array}$ \\
\hline Log (Total Words in the About Section) & $\begin{array}{l}0.178 * * * \\
(0.016)\end{array}$ & $\begin{array}{l}0.230^{* * *} \\
(0.058)\end{array}$ & $\begin{array}{l}0.065^{* * *} \\
(0.013)\end{array}$ & $\begin{array}{l}0.154^{*} \\
(0.084)\end{array}$ & $\begin{array}{l}0.346^{* * *} \\
(0.012)\end{array}$ & $\begin{array}{l}0.347^{* * *} \\
(0.074)\end{array}$ \\
\hline $\begin{array}{l}\text { Available Links to Websites by the } \\
\text { Entrepreneur }\end{array}$ & $-0.55^{* * *}$ & $-0.329^{* * *}$ & $-0.327^{* * *}$ & -0.079 & $-0.147^{* * *}$ & -0.057 \\
\hline & $(0.027)$ & $(0.112)$ & $(0.024)$ & $(0.163)$ & $(0.022)$ & $(0.145)$ \\
\hline US Based Project & $\begin{array}{l}-0.089^{*} \\
(0.051)\end{array}$ & $\begin{array}{c}-0.55^{* * *} \\
(0.184)\end{array}$ & $\begin{array}{l}-0.014 \\
(0.040)\end{array}$ & $\begin{array}{l}-0.522^{* *} \\
(0.233)\end{array}$ & $\begin{array}{l}-0.076^{* *} \\
(0.036)\end{array}$ & $\begin{array}{c}-0.663^{* * *} \\
(0.207)\end{array}$ \\
\hline Constant & $\begin{array}{l}2.194^{* * *} \\
(0.120)\end{array}$ & $\begin{array}{l}2.073^{* * *} \\
(0.440)\end{array}$ & $\begin{array}{l}-0.332^{* * *} \\
(0.087)\end{array}$ & $\begin{array}{l}-0.400 \\
(0.561)\end{array}$ & $\begin{array}{l}1.672^{* * *} \\
(0.079)\end{array}$ & $\begin{array}{l}2.489^{* * *} \\
(0.498)\end{array}$ \\
\hline Observations & 18,578 & 1,059 & 18,173 & 1,042 & 18,174 & 1,042 \\
\hline R-Squared / Pseudo R-Squared & 0.1158 & 0.1105 & 0.053 & 0.043 & 0.058 & 0.045 \\
\hline
\end{tabular}

Standard errors in parentheses. ${ }^{* *} \mathrm{p}<0.01,{ }^{* *} \mathrm{p}<0.05,{ }^{*} \mathrm{p}<0.1$ 
Figure 1

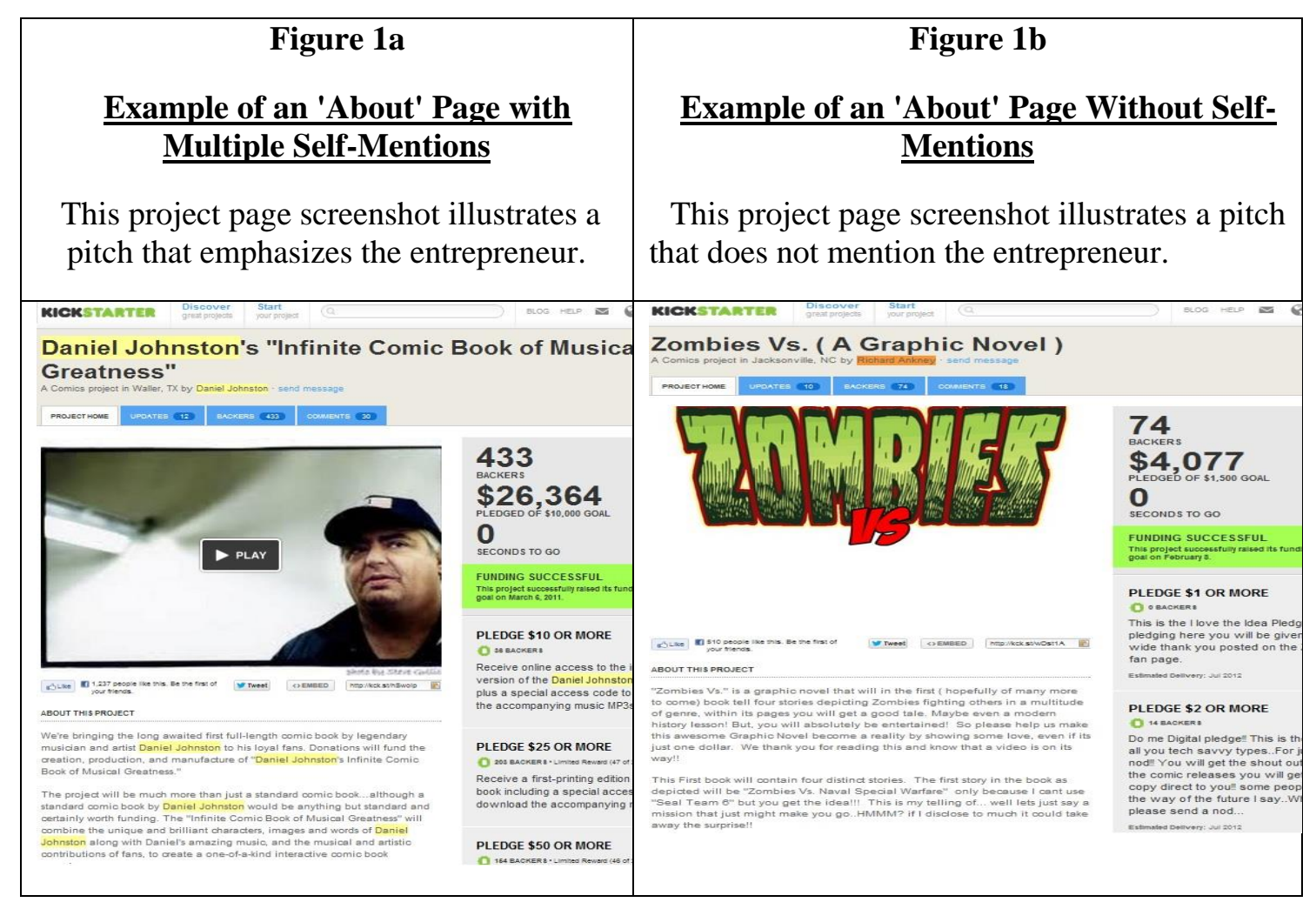


Figure 2

\section{$\underline{\text { Human Rating vs. Self-Mention Counts }}$}

This graph illustrates the human verification of our text analysis - human ratings of the relative emphasis placed on the entrepreneur (X-axis) vs. counted number of mentions from the text mining technique (Y-axis). The number reported on the graph is the mean Q2 response. We provide the confidence interval for each measure.

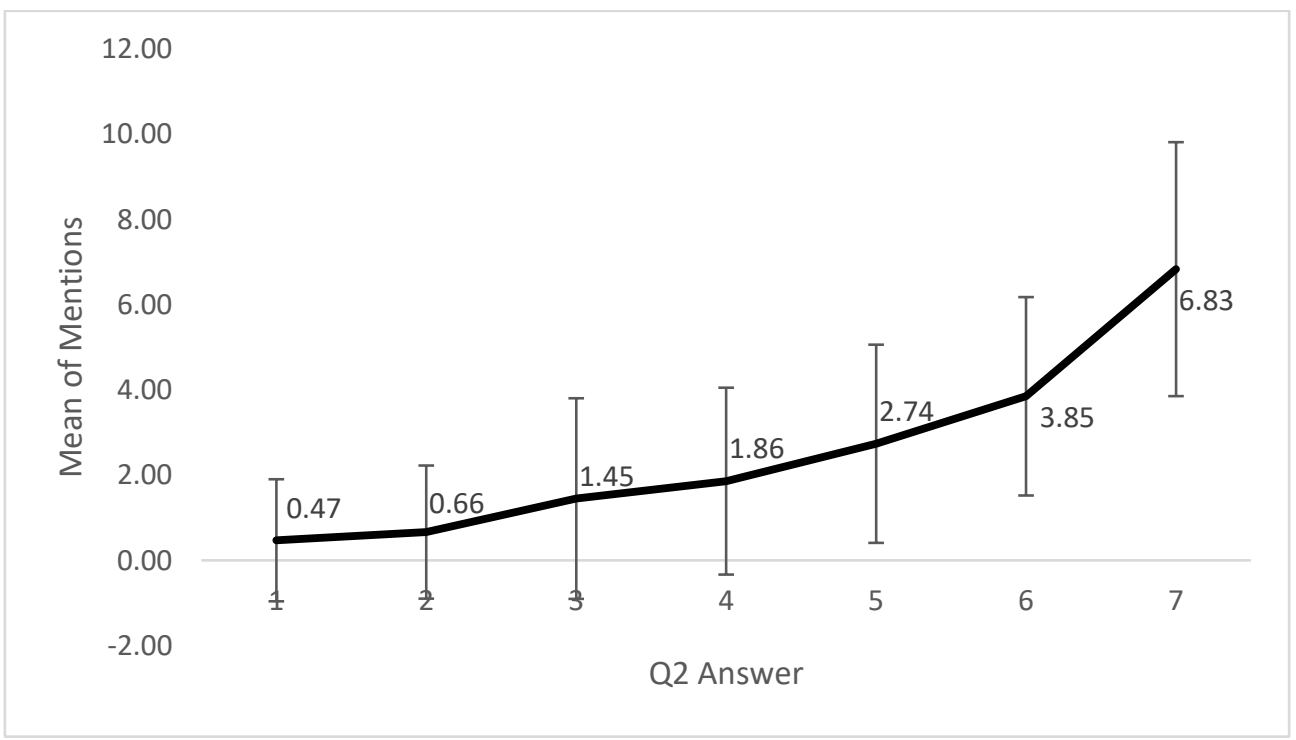




\section{APPENDIX A}

\section{Variables list table}

This table lists the project variables used to analyze the data set. Some of the variables were extracted directly from the data (Goal, Pledged, Investors, Category, Country), while obtaining others involved manipulation.

\begin{tabular}{ll}
\hline Variable & Definition \\
\hline Goal & The amount entrepreneurs seek to raise. \\
Pledged & The sum raised by the projects. \\
Investors & Number of users funding the project. \\
Category & Category of the project \\
Country & Country of the project \\
Success (dummy) & Dummy equal to 1 if the project reached its goal \\
Fail (dummy) & Dummy equal to 1 if the project failed to reach its goal \\
Experience (dummy) & Dummy equal to 1 if the entrepreneur had any prior projects on the site \\
No. of Previous Projects & The number of previous projects initiated by the entrepreneur \\
Previous Success (dummy) & Dummy equal to 1 if the entrepreneur's previous project reached its goal \\
No. of Successful Projects & The number of successful projects initiated by the entrepreneur \\
Video (dummy) & Dummy equal to 1 if a video is presented on the page \\
Words & Number of words used in the 'About' section \\
Patent (dummy) & A mention of a patent in the description of the project \\
Website (dummy) & Dummy equal to 1 if the entrepreneur provided a link to a website \\
\hline
\end{tabular}


Descriptive statistics of variables used in this analysis

\begin{tabular}{lllll}
\hline & Mean & Std. Dev. & Median & $90 \%$ \\
\hline Number of mentions & 0.717 & 1.392 & 0 & 2 \\
Number of mentions in first 100 words & 0.286 & 0.607 & 0 & 1 \\
A mention in the title (dummy) & 0.181 & 0.385 & 0 & 1 \\
Successful funding ("Reaching the goal") & 0.801 & 0.399 & 1 & 1 \\
\% Pledged & 2.555 & 110.509 & 1.0624 & 1.63 \\
Number of backers & 79.850 & 264.885 & 41 & 146 \\
Goal & 6,981 & 33,276 & 3000 & 14532.5 \\
Previous success of entrepreneur & 0.069 & 0.551 & 0 & 0 \\
Video on the project page & 0.517 & 0.500 & 1 & 1 \\
Total words in About section & 398.324 & 277.784 & 332 & 740 \\
Available links to websites (dummy) & 0.479 & 0.500 & 0 & 1 \\
US based (dummy) & 0.945 & 0.229 & 1 & 1 \\
\hline
\end{tabular}




\section{APPENDIX B}

This table presents the OLS Regression Results for the Effects of Antecedents on Funding Measures. The dependent variables are reaching the funding goal, $\%$ pledged and number of backers, and the independent variables are the entrepreneurial presentation measures (selfmentions in the title, video and links) and project attributes (goal, main category and location).

\begin{tabular}{|c|c|c|c|}
\hline & $\begin{array}{l}\text { Reaching } \\
\text { The Goal }\end{array}$ & $\%$ Pledged & $\begin{array}{c}\text { \# of } \\
\text { Backers }\end{array}$ \\
\hline & (1) & (2) & (3) \\
\hline Technological Main-Category & $\begin{array}{c}-0.309^{* * *} \\
(0.044)\end{array}$ & $\begin{array}{c}-0.082^{* *} \\
(0.041)\end{array}$ & $\begin{array}{c}0.421^{* * *} \\
(0.037)\end{array}$ \\
\hline A Mention in the Title & $\begin{array}{c}0.549^{* * *} \\
(0.033)\end{array}$ & $\begin{array}{c}0.274^{* * *} \\
(0.024)\end{array}$ & $\begin{array}{c}0.395^{* * *} \\
(0.022)\end{array}$ \\
\hline $\log ($ Goal) & $\begin{array}{c}-0.221^{* * *} \\
(0.010)\end{array}$ & & \\
\hline Previous Successes of Entrepreneur & $\begin{array}{c}-0.002 \\
(0.021)\end{array}$ & $\begin{array}{c}0.122^{* * *} \\
(0.017)\end{array}$ & $\begin{array}{c}-0.035^{* *} \\
(0.015)\end{array}$ \\
\hline Video on The Project Page & $\begin{array}{c}0.354^{* * *} \\
(0.028)\end{array}$ & $\begin{array}{c}0.322^{* * *} \\
(0.024)\end{array}$ & $\begin{array}{c}0.189^{* * *} \\
(0.022)\end{array}$ \\
\hline Log(Total Words in the About Section) & $\begin{array}{c}0.208^{* * *} \\
(0.016)\end{array}$ & $\begin{array}{c}0.083^{* * *} \\
(0.013)\end{array}$ & $\begin{array}{c}0.367^{* * *} \\
(0.012)\end{array}$ \\
\hline Available Links to Websites by the Entrepreneur & $\begin{array}{c}-0.539^{* * *} \\
(0.027)\end{array}$ & $\begin{array}{c}-0.312^{* * *} \\
(0.024)\end{array}$ & $\begin{array}{c}-0.136^{* * *} \\
(0.022)\end{array}$ \\
\hline US Based Project & $\begin{array}{c}-0.171^{* * *} \\
(0.049)\end{array}$ & $\begin{array}{c}-0.074^{*} \\
(0.040)\end{array}$ & $\begin{array}{c}-0.150^{* * *} \\
(0.036)\end{array}$ \\
\hline Constant & $\begin{array}{c}2.079^{* * *} \\
(0.116)\end{array}$ & $\begin{array}{c}-0.418^{* * *} \\
(0.087)\end{array}$ & $\begin{array}{c}1.55^{* * *} \\
(0.079)\end{array}$ \\
\hline Observations & 19,637 & 19,215 & 19,216 \\
\hline R-squared / Pseudo R-Squared & 0.134 & 0.057 & 0.075 \\
\hline
\end{tabular}

Standard errors in parentheses

${ }^{* * *} \mathrm{p}<0.01,{ }^{* *} \mathrm{p}<0.05,{ }^{*} \mathrm{p}<0.1$ 